\title{
Genome Mapping of Horticultural Crops
}

\author{
held at the \\ 92nd ASHS Annual Meeting \\ Montréal, Québec, Canada \\ 30 July 1995
}

\begin{abstract}
sponsored by the
Fruit Breeding Working Group

Viticulture and Small Fruits Working Group

Ornamental Plant Breeding Working Group

Vegetable Breeding Working Group

Plant Biotechnology Working Group

Genetics and Germplasm Working Group

Citrus Crops Working Group
\end{abstract}

published by the

American Society for Horticultural Science

Alexandria, VA 22314-2562

as a special insert in

HortScience 31(7), December 1996 


\title{
Colloquium Papers and Authors
}

\author{
Presiding: Ralph Scorza
}

Genome Mapping of Horticultural Crops: Introduction to the Colloquium

Ralph Scorza

Progress in Prunus Mapping and Application of Molecular Markers to Germplasm Improvement W.V. Baird, R.E. Ballard, S. Rajapakse, and A.G. Abbott

Application of Genetic Diagnostics to Plant Genome Analysis and Plant Breeding J.M. Vogel, A. Rafalski, W. Powell, M. Morgante, C. Andre, M. Hanafey, and S.V. Tingey

Progress of Apple Genetic Mapping in Europe

Graham J. King

Genetic Studies in Pea and Apple: The Yin and Yang of Mapping in Plants

Norman F. Weeden

Molecular Markers and Mapping in Bulb Onion, A Forgotten Monocot

Michael J. Havey, Joseph J. King, James M. Bradeen, and Ockyung Bark

\section{Genome Mapping of Horticultural Crops: Introduction to the Colloquium}

\author{
Ralph Scorza \\ U.S. Department of Agriculture, Agricultural Research Service, Appalachian Fruit Research Station, 45 Wilshire \\ Road, Kearneysville, WV 25430
}

There is a tremendous interest in genome mapping of crop species. A great part of this interest is focused on the use of maps for cultivar development. Genome mapping offers the possibility of selection at the DNA level, eliminating the uncertainty of environmental effects. In practical terms, a genome map would, among other uses, allow breeders to select for characters in young seedlings without the need for evaluation in the field for traits that are only expressed in mature plants, such as flower or fruit quality. An ideal map would preclude the need for inoculation and insect feeding trials when selecting potentially resistant seedlings. But can this map ever be realized considering the vast size of most plant genomes and the many important traits that must be field-evaluated in mapping populations in order to place them on a map? If the ideal map cannot be realized in the near future, what will a less-than-ideal map offer the breeder?

With the goals of answering these questions and improving our understanding of genome mapping in horticultural crops, our distinguished participants have presented theoretical and practical information on genome mapping on a diverse group of horticultural crops,

Received for publication 29 Nov. 1995. Accepted for publication 28 Jan. 1996. The cost of publishing this paper was defrayed in part by the payment of page charges. Under postal regulations, this paper therefore must be hereby marked advertisement solely to indicate this fact. including Prunus [mainly peach [Prunus persica (L.) Batsch], a selffertile woody perennial with a small genome and a limited germplasm base], apple (Malus $\times$ domestica Borkh.) (a highly heterozygous outcrossing woody perennial), onion (Allium cepa L.) (an outcrossing species with high levels of inbreeding depression and heterosis), and pea (Pisum sativum L.) (a widely studied species with a large genome, some well-characterized mutants, a linkage map, and well-defined genetics, but many chromosomal rearrangements). These species were selected to cover a wide range of considerations that would be applicable to most crops. A concise overview of the utility of some of the latest approaches in mapping is also presented, along with an update on the progress of some of the European mapping projects.

This is the best of times and the worst of times. We are on the verge of an exciting new technology that holds great promise to improve our effectiveness as breeders. But it is also a time of insecurity and uncertainty due to shrinking budgets. Difficult decisions must be made on the allocation of scarce resources between molecular technologies and field-based research, both of which are vital to breeding programs. For the breeder, a molecular map is not a goal but a tool to reach a goal- the improved cultivar. We, as breeders, now have the opportunity to work with molecular biologists in developing the tool. By taking part in this development we will more fully understand how best to use it. 


\title{
Progress in Prunus Mapping and Application of Molecular Markers to Germplasm Improvement
}

\author{
W.V. Baird \\ Department of Horticulture, Box 340375, Poole Agricultural Center, Clemson University, \\ Clemson, SC 29634-0375 \\ R.E. Ballard, S. Rajapakse, and A.G. Abbott \\ Department of Biological Sciences, 132 Long Hall, Clemson University, Clemson, SC 29634-1903
}

\begin{abstract}
In temperate regions of the world, the Rosaceae ranks third in economic importance. Its commercially valuable members include fruit-producing and ornamental species. Traditionally, the Rosaceae is divided into four well-defined subfamilies. One of these, the Prunoideae, is characterized by species that produce drupes as fruit, and this subfamily contains several important fruit [e.g., apricot (Prunus armeniaca L.), sour cherry (P. cerasus L.), sweet cherry (P. avium L.), plum (e.g., P. domestica L.), peach (P. persica (L.) Batsch)] and nut [almond (P. amygdalus Batsch = P. dulcis (Miller) D.A. Webb)] crops, and even a species grown for its wood (black cherry, P. serotina Ehrh.).

Since 1992, worldwide annual production has been about 10 million tons for peach and nectarine, 6 million for plums, and 123,000 tons for almonds. Of this total, the United States produces 14\%, 15\%, and $31 \%$, respectively (U.S. Dept. of Agriculture, 1993). Clearly, the contribution of Prunus species to the total world and U.S. fruit and nut crop production is significant. Although the available germplasm in this genus is diverse, many of the commercial Prunus species (i.e., peach, sour cherry, apricot, and plum) stem from a narrow genetic base (Iezzoni et al., 1991; Mehlenbacher et al., 1991; Ramming and Cociu, 1991). For example, the origin of most peach cultivars grown in the United States can be traced to a handful of seedlings imported directly from China (Schery, 1972). In fact, most modern selections can be traced to the cultivar Chinese Cling (Scorza et al., 1985). Additionally, the life cycle of these tree fruits, with its extended juvenile stage, complicates the design and implementation of standard breeding practices. This problem is compounded when the trait of interest (e.g., fruit quality or stress tolerance) is expressed only in sexually mature individuals or in response to complex biotic or environmental cues. For these reasons, technological advances that streamline breeding programs by quickly identifying desirable progeny via early assessment of phenotype potential will greatly improve industry productivity.
\end{abstract}

\section{DNA MARKERS}

The use of nucleic acid-based genetic markers has ushered in a new era in genome analysis and provides new, much-needed tools to the breeder. The genetic variation detected by these markers can be used, for example, to identify and discriminate closely related cultivars; to assess taxonomic and phylogenetic relationships; for pedigree analysis, linkage mapping, and indirect selection of tagged loci affecting qualitative or quantitative traits; and to monitor loci during introgression or selection programs, and thus reduce the number of backcross generations. Because DNA polymorphisms are more abundant than conventional morphological or biochemical markers, they are particularly well suited to chromosome mapping in species where crosses are difficult to make (i.e., markers can be identified and a map developed

Received for publication 29 Nov. 1995. Accepted for publication 28 Jan. 1996. Technical contribution no. 4129 from the South Carolina Agricultural Experiment Station. Financial support provided by the USDA/NRICGP Plant Genome Program (93-37300-8818) and the NSF-EPSCoR (R11-8922165). We thank D.G. Heckel (CU) and an anonymous reviewer for careful review of the original manuscript. We also thank Linda Belthoff, Agnes Estager, Guohao He, Bryon Sosinski, Manjula Gannavarapu, and John Wells for technical support and editorial comments. The cost of publishing this paper was defrayed in part by the payment of page charges. Under postal regulations, this paper therefore must be hereby marked advertisement solely to indicate this fact. in a single segregating population). Molecular markers offer many other advantages over conventional phenotypic markers. They are 1) developmentally stable, 2) detectable in all tissues, 3) unaffected by environmental conditions, 4) virtually insensitive to epistatic or pleiotropic effects, and 5) provide a choice of codominant or dominant marker subclasses (Botstein et al., 1980; Helentjaris et al., 1985; Williams et al., 1990). The potential abundance of molecular markers has the added advantage of increasing the probability of tagging complex, multigene traits, as well as those controlled by single genes. Molecular marker-based genetic maps allow the development and efficient use of indirect selection schemes for germplasm improvement, thereby increasing precision in the manipulation of both qualitative and quantitative traits.

\section{Hybridization-based markers}

An array of DNA-based marker systems is available. The first broadly applicable marker system detected variation in the length of DNA segments. These polymorphisms are revealed by digesting genomic DNA with a restriction endonuclease and screening the resulting fragments by Southern hybridization with a labeled DNA probe (Botstein et al., 1980; Kan and Dozy, 1978; Wyman and White, 1980). Therefore, these genetic markers are termed restriction fragment length polymorphisms (RFLPs). RFLP markers are codominant. Their use has fundamentally changed the genetic characterization of plant germplasm and is contributing significantly to map-based selection in many breeding programs. They are well suited for linkage map development and phylogenetic comparisons, as homologous RFLPs can be identified across a wide evolutionary range (Ahn and Tanksley, 1993).

Despite this power and utility, RFLP analysis has its shortcomings. For example, the process is time-consuming and labor intensive. An attempt to overcome such drawbacks, especially for repeated analysis of specific regions of the genome, resulted in the development of sequence-tagged sites (STS) (Olson et al., 1989; Tragoonrung et al., 1992). In STS analysis, oligonucleotides are synthesized (based on a unique DNA sequence from cloned RFLP probes) for use with the polymerase chain reaction (PCR) (Saiki et al., 1985). Other limitations of RFLP analysis include: 1) the expense of developing each informative probe-enzyme combination, 2) the tedious and cumbersome nature of marker management and dissemination, and 3) the difficulty with automating the procedures. Also, for many self-pollinated or highly inbred crops, RFLP analysis reveals only a few alleles per locus.

\section{Amplification-based markers}

A major advancement in germplasm analysis and mapping occurred with the discovery of a heat-stable DNA polymerase and, in conjunction with an automated temperature cycler, the development of PCR (Mullis et al., 1986). PCR-based methods allow the rapid detection of DNA polymorphisms from many individuals or pooled samples. The last few years have witnessed several useful advancements in PCR-based technologies. In general, these methods use a series of very short oligonucleotide primers, sometimes of arbitrary sequence, that amplify one or more regions of the genome. Ideally, this will produce a DNA banding pattern unique to each primer or primer pair. The banding pattern can be visualized directly through staining without the intervening need for blotting and hybridization with 
labeled probes, as used in RFLP analysis. These approaches have an advantage in that no prior knowledge of the target DNA sequence is needed to initiate the analysis, although such information can be very useful. Other advantages include the high levels of DNA polymorphisms detected, lower cost, and the adaptability of the procedure to automation.

One method based on PCR, now referred to as random amplified polymorphic DNA (RAPD), was developed simultaneously in two independent laboratories (Welsh and McClelland, 1990; Williams et al., 1990). RAPD techniques involve PCR amplification of genomic DNA using a single arbitrary primer (usually 10 nucleotides), separating amplified products by agarose gel electrophoresis, and visualizing them using ethidium bromide staining.

A second PCR-based method, DNA amplification fingerprinting (DAF), involves using arbitrary primers as short as five nucleotides, reducing the stringency of primer-template annealing, and visualizing the amplification products on silver-stained polyacrylamide gels (Bassam et al., 1991; Caetano-Annoles et al., 1991). DAF produces detailed but relatively complex DNA profiles in a wide variety of organisms, including plants. This method is most suitable for genetic identification studies. DAF already has some refinements that increase detection of polymorphic DNA (e.g., prior digestion of template DNA with 1-3 restriction endonucleases or using mini-hairpin primers) and can be used to differentiate closely related cultivars and near isogenic lines (Caetano-Anollés and Gresshoff, 1994; Caetano-Anollés et al., 1993).

Disadvantages of some of these early PCR-based technologies included the typically dominant nature of the markers, the sometimes poor reproducibility, the lack of primer sequence homology among related taxa, and the presence of faint or false amplification products that cannot be scored confidently (Weeden et al., 1992). One way to overcome these limitations is the conversion of a PCR-based marker into a codominant RFLP probe or sequence-characterized amplified region (SCARs). SCARs are polymorphic PCR products, first identified using random decamer primers, that have been sequenced and unique primers designed for their specific amplification. In addition, the specificity of these markers makes them suitable for use in positional cloning (Paran and Michelmore, 1993). A recent symposium review article (Kelly, 1995) provides an excellent discussion of the utility, advantages and limitations of molecular markers, in particular RAPDs, in crop breeding programs.

Simple sequence repeats (SSRs) of extremely high polymorphic content represent another important modification of PCR-based molecular marker technology. SSRs, consisting of tandem repeats of $\leq 6$ bp [e.g., $(\mathrm{GT})_{\mathrm{n}}$ or $(\mathrm{GATA})_{\mathrm{n}}$ ], are usually termed microsatellites (Litt and Luty, 1989; Weber and May, 1989). The copy number of these repeats, which can vary among individuals, provides the basis for the polymorphism(s). This method is rapidly gaining importance in plant genome analysis (Condit and Hubbell, 1991; Rangwen et al., 1995).

Another recently developed PCR-based method is amplified fragment length polymorphism analysis or AFLP (Vos et al., 1995), also referred to as selective restriction fragment amplification. The template for this method is double restriction endonuclease (RE)-digested DNA to which RE-specific adapters are ligated. Then a series of unique RE-specific primers with additional 3'-nucleotide(s) are used to selectively amplify $\approx 50$ products that are separated in denaturing polyacrylamide gels. This proprietary technology holds great potential for molecular linkage map development and DNA "fingerprinting" applications. Its use and availability has been made more convenient by the recent introduction of commercial kits. For further discussion of other recent advances in molecular marker system development, the reader should investigate a companion article from this symposium (Vogel et al., 1996).

\section{Comparison and evaluation of DNA markers}

With so many molecular marker systems and modifications, recent efforts have begun to focus on comparing and contrasting these various methodologies. Ragot and Hoisington (1993) compared the expense of genotyping diverse plant germplasm and concluded that RFLPs were more cost effective in large populations, but that RAPDs may be a better choice for smaller ones. Other studies investigating genetic relationships in herbaceous crop species have focused attention on evaluating one marker system in comparison to another. For example, Thormann et al. (1994) and Santos et al. (1994) independently concluded that RFLPs and RAPDs provide equivalent utility and levels of resolution when applied to estimating intraspecific genetic similarities. In addition, Santos et al. (1994) concluded that most observed differences revealed by these two methodologies were the result of sampling error rather than fundamental differences in how the methods detect DNA-based polymorphisms. However, Thormann et al. (1994) concluded that RAPD data may be less reliable when estimating genetic relationships at the interspecific level. Most recently, Powell et al. (1995) investigated the relative utility, expressed as marker index (MI) values [a numerical product of the marker's expected heterozygosity and the multiplex ratio (number of polymorphic products per "reaction")], of various molecular marker systems. Although these data were obtained from work in soybean (Glycine $\max$ L.), they are likely to be directly applicable to other crops. Powell et al. (1996) determined that dinucleotide SSRs had the highest expected heterozygosity (almost twice that of RFLPs and RAPDs). In contrast, AFLPs had the highest multiplex ratios (more than an order of magnitude greater than SSRs). The conclusions of this study showed that MI values for AFLPs, SSRs, RAPDs, and RFLPs were $6.14,0.60,0.48$, and 0.10 , respectively.

\section{LINKAGE ANALYSIS, MARKER-ASSISTED SELECTION, AND MAP CONSTRUCTION}

The effectiveness of DNA-based systems for use in markerassisted selection (MAS) or positional, map-based gene cloning lies in the contiguity of a marker's linkage to the gene of interest. To a first approximation this can be measured by converting recombination frequency into map distance, measured in centiMorgans (cM). The higher the co-inheritance (i.e., closer the linkage) between a marker(s) and the gene of interest, the more effective selection based on that marker will be. A marker should be well within a few centiMorgans of the gene for consideration for use in MAS.

The cosegregation data between pairs of markers or between combinations of marker pairs are used to define and identify specific genetic linkage groups that correspond to the physical chromosomes. Marker order in a linkage group is calculated by multipoint analysis using maximum likelihood or simulated annealing approaches. The effective application and use of various linkage analysis and map construction software depends on matching assumptions made by the program developers with the biological realities of the plant species under investigation. These factors include population types (e.g., $\mathrm{F}_{1}$, $\mathrm{F}_{2}$, backcross, etc.), species biology (e.g., level of inbreeding, outcrossing, heterozygosity, etc.), trait genetics (e.g., single gene, segregation ratio, complex inheritance, etc.), and marker characteristics (e.g., codominant or dominant, coupling or repulsion phase, etc.).

MAPMAKER, developed at the Whitehead Institute, Cambridge, Mass., USA (Lincoln et al., 1992a), is the most widely used program for constructing primary linkage maps using simply inherited traits in various types of populations such as backcrosses, $F_{2}$ and $F_{3}$ intercrosses, and recombinant inbred lines. It uses the maximum-likelihood method to calculate rate of recombination and gene order within linkage groups. MAPMAKER is available for use with personal computers running DOS-, Unix-, or Macintosh-based systems. It can be obtained through the Internet via anonymous FTP from host "genome.wi.mit.edu". MAPMAKER for Macintosh (except v. 3.0) is available from Scott Tingey at the DuPont Experimental Station at Wilmington, Del., USA. The loci for genes controlling quantitative traits (QTLs) can be mapped using MAPMAKER/QTL version 1.1 (Lincoln et al., 1992b).

JOINMAP was developed by Piet Stam at the Center for Plant Breeding and Reproduction Research, Wageningen, The Netherlands (Stam, 1993). Like MAPMAKER, JOINMAP can construct maps from single crosses, but it also has the advantage of merging maps obtained from distinct experiments and published recombination frequencies that are important in comparative mapping. Unlike MAPMAKER, JOINMAP can also be used with markers segregating 
in various ratios $(3: 1,1: 1$, etc.) within the same cross. Versions are available for operating systems such as DOS, VMS, Unix, and Macintosh. A simulated annealing algorithm is implemented in ordering markers in GMENDEL, a program developed by Liu and Knapp at Oregon State Univ., Corvallis, USA (Liu and Knapp, 1990). MAPRF, developed by Enrique Ritter at the CIMA institute, Arkaute, Spain, is a program for constructing genetic linkage maps using RFLP markers in allogamous species. This program is for use with DOS operating systems. The basic outline of this method is described in detail by Ritter et al. (1990). LINKAGE-1 (Suiter et al., 1983) is another package used for two-point linkage analysis by many researchers. RI Plant Manager, developed by Kenneth Manley at the Roswell Park Cancer Institute, Buffalo, N.Y., is a marker database and analysis program for genetic mapping with recombinant inbred lines and multilocus backcrosses. TwoPtLep and MapaLep are programs designed for linkage analysis in species in which only one sex has crossing over (Shi et al., 1995). QTL Cartographer is a program for mapping QTLs (Basten and Zeng, 1995). PGRI (Plant Genome Research Initiative) is a new computer package for linkage mapping, QTL mapping, and progeny and parent selection for genome mapassisted plant breeding programs (Lu and Liu, 1995). The LINKEM program (Vowden et al., 1995) has the advantages of accomplishing linkage analysis for loci pairs having any possible parental phase combination.

In addition to developing molecular linkage maps for use in reaching specific breeding objectives, nucleic acid-based marker data can be informative in studies designed to elucidate genetic relationships within and between the various Prunus taxa. Various statistical algorithms are available for such genetic similarity analyses. These include analytical packages either adapted to or written specifically for molecular data, such as SAS (SAS, 1990), Nei-Li similarities (Nei and Li, 1979), PAUP (Swofford, 1991), and PHYLIP (Felsenstein, 1988), and those by Efron and Tibshirani (1986), Excoffier et al. (1992), Mantel(1967), Rohlf(1992), and Wilkinson(1989). This information, in turn, can be used to devise in vitro identification schemes for the various species and cultivars (see the Cultivar Identification section, below).

\section{Marker-assisted selection}

Indirect, phenotype-based selection of important agronomic traits is a time-honored breeding method. Such traditional "morphologicalmarker-assisted selection" suffers from low marker availability (as some markers represent deleterious mutations in their own right), pleiotropy, confounding epistatic effects, and environmental instability. Molecular MAS, in contrast, has the potential to avoid or overcome these limitations (Melchinger, 1990). Also, its potential as a mechanism to maximize heritability and increase gains from selection for quantitative traits is an important topic of investigation (Knapp, 1994). Furthermore, MAS can be effective in the absence of a complete and uniformly saturated molecular linkage map.

One advantage to using molecular markers in selection schemes, as stated earlier, is that DNA-based markers are essentially limitless. Also, the identification of one or more tightly linked molecular markers allows efficient selection for the presence of a specific trait in progeny where its expression is absent (e.g., developmentally regulated or inducible only by biotic or abiotic stress) or when its expression is masked by that of other genes. Selection efficiency is further increased when markers flank or bracket the locus (loci) of interest, because errors resulting from recombination are minimized. This feature can be particularly important in designing strategies of "pyramiding" multiple loci affecting a complex "single" trait (e.g., pathogen resistance).

If sufficient mapping information is known, MAS can significantly shorten the number of generations required to "eliminate" the genome of the donor parent in backcrossing programs (as well as in modified backcrosses, which are more common in many fruit and nut tree breeding programs) (Mehlenbacher, 1995). Many of the mapping projects have as one of their objectives the MAS of one or more characters for trait-quality maintenance, overall germplasm improvement, or both.
The utility and efficient application of MAS to identify the most appropriate line(s) for advancement lies in understanding the limitations of the system and correctly identifying the critical variables. These are factors such as trait heritability (usually low for important agronomic traits), choice of optimal sample size (e.g., number of lines and replications to evaluate), and program resources (e.g., cost of each trait or marker analysis in time and money, germplasm resources, etc.). Once these factors are considered, MAS based on a marker only or marker-index system may not always be more effective and efficient than phenotype selection schemes (Knapp, 1994). Another problem associated with MAS when using mapping data derived from interspecific crosses is that of map (or linkage) compression (Kelly, 1995; Paterson et al., 1990). This phenomenon is manifested as differences in genetic distance such that loci appear more closely associated (i.e., genetically linked) in a wide cross than they are in populations derived from crosses between more closely related individuals (i.e., intraspecific). This divergence is most likely due to linkage drag, resulting from suppression of recombination in the newly created hybrid germplasm. The outcome for the breeder can be markers that are partially or completely ineffective for one breeding program or the other.

\section{Genome mapping}

As illustrated in the following section, two distinct objectives have been addressed in efforts to identify informative molecular markers and construct molecular linkage maps in Prunus spp. Emphasis has either been placed on developing a map of benefit to breeders, by tagging traits of economic importance in a particular fruit or nut crop, or to develop a core Prunus map, providing "generic" landmarks and identifying conserved islands of chromosome homology between numerous species. These studies typically start with a survey of available germplasm in an effort to gauge the level of molecular polymorphism available through one marker system or another. In addition, experimental germplasm and segregating populations have been derived from intraspecific (i.e., peach $x$ peach) and interspecific crosses [e.g., peach $\mathrm{x}$ almond; peach $\mathrm{x} P$. davidiana (Carr.) Franch]. The advantage of the latter approach is that such populations likely show more polymorphism than those derived from intraspecific $F_{1}$ hybrids.

Most of the initial efforts in mapping the Prunus genome began with peach, which is a result of its economic importance and geographical distribution; also, peach is the best characterized species in the genus and one of the best genetically characterized fruit crops overall (Mowrey et al., 1990). Peach, a diploid species with $2 \mathrm{n}=16$ (Jelenkovic and Harrington, 1972), has a remarkably small nuclear genome containing $\approx 0.30 \pm 0.02 \mathrm{pg}$ of DNA per haploid nucleus, or about $3 \times 10^{8}$ bp (Baird et al., 1994). However, comparatively little is known about its genome structure and organization. For example, no cytogenetic markers have been identified for the somatic chromosomes of peach, although $\approx 25$ morphological (Monet, 1989; Monet et al., 1985) and 10 isoenzyme traits (Monet, 1989; Mowrey et al., 1990) have been described. Unfortunately, the latter group has shown consistently little polymorphism in this principally autogamous species (Arulsekar et al., 1986a, 1986b; Durham et al., 1987; Mowrey et al., 1990).

Surprisingly, and until only recently (Chaparro et al., 1994, 1995a), only three pairs among the more than 40 simply inherited traits were known to show linkage (Hesse, 1975; Monet et al., 1985; Yamazaki et al., 1987). This aspect may be partially explained by the fact that few experimental lines exist where two or more of these monogenic traits have been combined to facilitate genetic studies in peach. This shortcoming is exacerbated in other, less well-characterized species of Prunus. Also, the possibility of using tissue culture and somatic cell genetics is limited because few of the available genetic markers display a detectable phenotype in in vitro culture. These facts, combined with a long generation time, preclude development of a genetic linkage map for commercial peach or any of the Prunus spp. using conventional methods. Early reports, however, clearly demonstrated the utility of molecular markers to make rapid progress in map development and gene tagging (Abbott et al., 1990, 1991, 1992; Chaparro et al., 1992; Eldredge et al., 1992). 


\section{Prunus projects in the United States}

Peach. Genome mapping efforts at Clemson Univ., in collaboration with the U.S. Dept. of Agriculture's Appalachian Fruit Research Station (Kearneysville, WV), have been directed at examining three peach populations derived from intraspecific crosses representing widely different pedigrees. The first project involves mapping genes responsible for tree shape and form, such as pillar $(\mathrm{Pi} / \mathrm{Br})$, dwarf $(\mathrm{Dw})$, and compact $(C t)$. Compared to the standard spreading type, the pillar form has a distinctive columnar growth habit with acute branch angles and therefore an increased potential for high-density production systems, which can significantly increase yield per unit area of orchard. This map was developed from segregation analysis of $71 \mathrm{~F}_{2}$ individuals derived from the self-fertilization of four $F_{1}$ individuals of a cross between 'New Jersey Pillar' and KV 77119. This progeny is designated as the WV family. In addition to canopy shape, this family segregates for genes controlling fruit flesh color $(Y)$, flower size $(S h)$, petal number $(D l)$, and color $(W)$. The map developed for this population currently consists of 47 linked markers, both RFLPs and RAPDs (Rajapakse et al., 1995). The map identifies the eight linkage groups and covers $332 \mathrm{cM}$ of the peach genome with an average spacing of 8 $\mathrm{cM}$. The genes controlling the pillar tree shape and number of flower petals, $P i$ and $D l$, are linked $(17.6 \mathrm{cM})$ on linkage group 1 .

A second mapping project focuses on genes responsible for peach fruit quality (e.g., fruit size, flesh color, blush, acid and sugar content, and softening) and cold hardiness. To map the loci for these single and complex gene traits, we are using $200 \mathrm{~F}_{2}$ progeny of an intraspecific cross between 'Sun Crest' and 'Bailey'. These $\mathrm{F}_{2}$ progeny are produced from the self-fertilization of four $\mathrm{F}_{1}$ plants from this cross. We have identified more than 80 markers consisting of RFLPs obtained with peach genomic clones, as well as leaf cDNA clones and RAPDs. Of the 45 RFLP loci mapped in the WV family ('New Jersey Pillar' and KV 77119), 36\% were also polymorphic in this cross, thereby making direct comparisons between the two maps possible. So far, two pairs of linked markers (B7F6a and B7H2U; B8A3 and B8F6U) mapped in the WV family also were found linked in the 'SunCrest' $x$ 'Bailey' cross. In the 'Sun Crest' $x$ 'Bailey' cross, the level of polymorphism was very low (5\%) when cDNA clones were used as probes compared to genomic clones, where about $15 \%$ to $20 \%$ were polymorphic. In both crosses, about half of the RAPD primers tested detected polymorphism, but no more than $10 \%$ of RAPD markers developed in the earlier cross were polymorphic in this second cross. Screening continues for RFLP and RAPD markers and has been expanded to include SSR (microsatellites) and AFLP markers.

The third peach mapping project at Clemson Univ. involves using $\mathrm{F}_{2}$ progeny to map genes for resistance to root-knot nematodes [Meloidogyne incognita (Kofoid \& White) Chitwood]. The progeny were derived from a cross between peach cultivars 'Nemared' (resistant) and 'Lovell' (susceptible). Both RFLP and RAPD markers are being used to screen the parents, four $\mathrm{F}_{1}$ hybrids, and more than $100 \mathrm{~F}_{2}$ progeny from each $\mathrm{F}_{1}$ (X.Z. Lu and G. Reighard, pers. comm.).

Molecular markers should be easily generated and transferred to crosses that are currently available, especially for a map to be useful where segregating populations are not easily generated and many agronomic traits are not expressed in the juvenile condition. From our peach data, we have found that RFLP markers are ideal as "anchor loci" between crosses. For example, the three intraspecific populations we examined show that $35 \%$ to $55 \%$ of the markers from the WV family detect polymorphic loci in either of the other two crosses (Rajapakse et al., 1995). This high degree of shared polymorphism is lacking for RAPD loci where we found only $10 \%$ of RAPD markers to be transferable to other crosses (R. Ballard, unpublished). This finding implies a potential inadequacy of RAPDs for multiple genome comparisons. Others also have reported difficulties in establishing homologies between RAPDs initially identified from different individuals of the same species (Grattapaglia and Sederoff, 1994). This situation, if a general phenomenon, is disappointing since RAPD markers are more easily identified than RFLPs and, at least in theory, RFLPs presumably lack sufficient levels of polymorphism in selfpollinated species for efficient use (Nodari et al., 1992).

In collaborative projects between laboratories in Forestry and
Horticulture at North Carolina State Univ. (Chaparro et al., 1994), nine intraspecific $\mathrm{F}_{2}$ populations of peach were analyzed for linkage relationships between two isoenzyme loci (e.g., Catl and Mdhl) and 14 morphological loci [e.g., double flower $(\mathrm{Dl})$, pillar $(\mathrm{Br} / \mathrm{Pi})$, red leaf $(G r)$, white flower $(W)$, fruit epidermal hair $(G)$, yellow flesh color $(Y)$ ], and 83 RAPD markers (from a total of 520 primers screened). All the RAPDs, $M d h l$, and four morphological markers were assigned to 12 independent linkage groups as mapped in a single $\mathrm{F}_{2}$ family derived from NC174RL x 'Pillar'. $B r$ was linked to $D l(8.2 \mathrm{cM})$, and a number of RAPD markers were identified that flanked these two loci. Using bulked segregant analysis (Michelmore et al., 1991), a single RAPD was linked to $G(23.4 \mathrm{cM})$, and the region around $G r$ was saturated with 10RAPD markers. More recently, Chaparro et al. (1995a) 1) described the tissue- and organ-specific distribution of anthocyanins in various expression phenotypes of peach, 2) demonstrated that the white flower phenotype in the cultivar Pillar results from a mutation late in the anthocyanin pathway, and 3) reported that analysis of the $G r$ and $W$ genes in three $\mathrm{F}_{2}$ families revealed that these genes segregate independently and demonstrate recessive-type epistatic interaction. Chaparro et al. (1995b) also investigated variegation in anthocyanin production in vegetative and reproductive tissues of 'Pillar'. This phenotype is heritable, but with high reversion rates, and the genetic results support the hypothesis that the unstable phenotype is caused by an active transposable element (Chaparro et al., 1995b).

Peach $x$ almond. Using the $\mathrm{F}_{2}$ population derived from an interspecific cross between a dwarf peach (54P455) and an almond ('Padre'), a low-density Prunus map is being constructed at the Univ. of California, Davis (Foolad et al., 1995). The map covers $\approx 800 \mathrm{cM}$ on nine linkage groups and is composed of $>100$ markers, including 75 peach mesocarp cDNAs, 14 almond and 12 plum genomic clones, 6 isoenzymes, and one morphological trait $(D w)$. Eleven additional markers (five isoenzyme and six RFLP) remain unlinked. Three cDNA clones were found to be tightly linked (within $1 \mathrm{cM}$ ) to the $D w$ locus. Not surprisingly, a high level of segregation distortion (37\%) was observed in this population, probably due to the degree of reproductive incompatibility between the parental material and to the interspecific nature of the $F_{1}$ hybrid and $F_{2}$ progeny. Using bulked segregant analysis (Michelmore et al., 1991) in two other populations, three to five RAPD markers were linked to each of two isoenzyme loci (Mdhl and Aatl) and the flesh color locus $(Y)$. A subset of these RAPD markers were also polymorphic in the original peach $X$ almond mapping population and allowed the tentative localization of $Y$ and $M d h 1$ to the core map (Warburton and Bliss, 1995). Future efforts from the Univ. of California, Davis, group will be directed at identifying gene loci associated with tree growth and form, and with fruit ripening and mesocarp development in peach and almond.

Cherry-sweet and sour. Amy Iezzoni and her coworkers in the Horticulture Dept. at Michigan State Univ. (MSU) are developing a molecular linkage map to characterize the nuclear genome of sour cherry. Sour cherry $(2 n=32)$ is thought to be a naturally occurring allotetraploid between ground cherry ( $P$. fruticosa Pall.) and sweet cherry. Owing to incomplete allosyndetic pairing (diploidization), the fertility of sour cherry is low, thereby limiting fruit set and yield. The project's primary objective is to identify and tag regions of the sour cherry genome that exhibit allosyndetic pairing. Such a map would aid the breeder in screening germplasm collections for parents with the highest degree of diploidization, thus identifying parental plants with increased autosyndetic pairing. In other words, these markers would provide the breeder with a quantitative method of choosing parent plants whose genetic combination would result in the largest regions of regular pairing between homologous chromosomes, and the most potential to produce offspring having high fruit set. In addition, loci controlling 10 important phenological and morphological traits, such as bloom date, flower bud freeze susceptibility, and flesh color, will be mapped using a 'Rheinische Schattenmorelle' $x$ 'Erdi Botermo' cross.

The MSU group is also developing a low-resolution molecular linkage map for 'Emperor Francis', a sweet cherry cultivar (Stockinger et al., 1996). This map was constructed from 56 individuals regenerated from microspore-derived callus cultures. The map contains 87 RAPDs and two isoenzyme markers that map to 10 linkage groups totaling $503 \mathrm{cM}$. Interestingly, five RAPD markers, cloned for use as 
probes of genomic Southern blots, recognized putative homologous regions in ground cherry and sour cherry.

In addition, Iezzoni and her group are taking a novel approach among Prunus researchers in analyzing the molecular organization of the chloroplast genome to better understand the parentage of sour cherry, as well as determine the inheritance of this organelle. Initial results using North American accessions of sour cherry and its proposed progenitor species are encouraging. Both RFLP (two) and RAPD (four) markers were identified that showed sour cherry combined polymorphisms unique to each of its putative parents (Brettin and Iezzoni, 1995). However, the inclusion of Old World accessions in the study has complicated the analysis, and it will likely be necessary to identify more polymorphisms if a clear picture of cherry phylogenetics on a worldwide scale is to emerge (A. Iezzoni, pers. comm.). Nonetheless, their current findings support the hypothesis that chloroplasts are exclusively maternally inherited, and future efforts are directed at conclusively demonstrating this phenomenon.

Plum. The plums (hexaploid and diploid species, cultivated diploid hybrids, and wild relatives) represent the most heterogeneous crop commodity in Prunus. Investigations using molecular genetic markers have recently been initiated to better understand their phylogenetic relationships. Boonprakob and Byrne (1995) recently reported on efforts to use RAPD polymorphisms to estimate the genetic relatedness of diploid plums. The researchers showed that, for available species within the sections Euprunus and Prunocerasus of the subgenus Prunus (= Prunophora), the level of detectable molecular polymorphism was useful in measuring genetic distances and constructing phenograms. This work extends the utility of RAPDs beyond basic germplasm identification as reported by Gregor et al. (1994) for cultivars of $P$. domestica. Overall, Boonprakob and Byrne's preliminary findings mimicked currently understood gene pool relationships (e.g., germplasm clustered by known species and natural geographic distribution). Interpretation of their RAPD data for the hybrid species, however, was not as straightforward and will require further effort to identify more informative markers.

Apricot. A single study has investigated the utility of RAPD markers to consistently detect polymorphisms in apricot germplasm (Gogorcena and Parfitt, 1994). The material screened consisted of the cultivar Royal and six semi-wild accessions, originally collected from Pakistan. The authors found that seven of the 15 primers revealed informative, reproducible polymorphisms. In a related study, research groups at Kobe Univ. and the Fruit Tree Research Station in Ibaraki, Japan, reported on their collaborative efforts to determine the genetic relationships and classification of mume (Prunus mume Sieb. et Zucc.), including the Anzu- or Bungo-mume (i.e., apricot $x$ mume hybrids). Using 95 RAPD primers on genomic DNA from 54 cultivars, these researchers concluded that mume is composed of seven related groups consistent with either their fruit size, flower color, or hybrid pedigree (Shimada et al., 1994). The researchers believe that the RAPD markers they identified will be useful in identifying mume cultivars and that RAPD analysis will help resolve the relationship among mume and apricot cultivars.

\section{European Prunus projects}

Currently, a European research consortium, consisting of six laboratories in England, France, Italy, and Spain and headed by P. Arús [Institut de Recercai Tecnologia Agroalimentaries (IRTA), Barcelona, Spain], is attempting to obtain a saturated genetic map for Prunus (peach, almond, plum, apricot, and cherry) in 4 years. Cooperative efforts of this magnitude will certainly speed the use of molecular diagnostics in this important genus. At the IRTA Plant Genetics Dept., molecular map construction in almond is underway using intraspecific crosses between different almond cultivars (Ferragnes $x$ Tuono) and interspecific peach $x$ almond crosses ('Earlygold' $x$ 'Texas'). This mapping effort developed out of initial investigations of the inheritance of 10 isoenzyme genes among crosses of five almond cultivars (Arús et al., 1994b). The almond-specific map consists of $\approx 127$ markers (e.g., 120 RFLPs and seven isoenzyme loci). RFLPs were detected using 57 genomic and 43 cDNA almond clones (Viruel et al., 1995). Eight of the cDNA probes corresponded to known genes (seven cloned from almond and one from peach), and their successful use in this study should encourage further efforts to use homologous and heterologous gene probes in map construction.

Two maps were developed, one with 93 loci heterozygous in 'Ferragnes' and another with 69 loci in 'Tuono'. Thirty-five loci $(28 \%)$ were heterozygous in both parents and were used as anchor loci to bridge between the two maps. Eight linkage groups were found for each map covering 393 and $394 \mathrm{cM}$ in 'Ferragnes' and 'Tuono', respectively. Most recently, 53 RAPD markers have been added to the core almond map, including two RAPD markers proximal to the gene controlling kernel taste. An additional RFLP marker has been linked to the gene controlling shell hardness (P. Arús, pers. comm.). A report on their progress with the peach $\mathrm{X}$ almond map, including a comparison of this map with that of almond, is in preparation (P. Arús, pers. comm.). In addition, this consortium is mapping a 'Stella' almond $x$ cherry population, again with the intent of contributing to a consensus map for Prunus (Arús et al., 1994a). A practical goal of these mapping efforts will be to assist the intergeneric transfer of self-fertility to almond and to tag alleles for canker (Cytospora leucostoma Sacc.) resistance.

Dirlewanger and Bodo (1994) used an intraspecific $F_{2}$ peach population to investigate the inheritance of the weeping growth habit $(P l)$, nectarine fruit type $(G)$, and resistance to peach aphid [Myzus persicae (Sulzer)] $(\mathrm{Rml})$, and to identify molecular markers linked to these loci. Thirty-eight RAPD primers revealed 52 polymorphic markers, from which a map covering $350 \mathrm{cM}$ of the peach genome and identifying eight linkage groups was constructed. Four RAPDs remained unlinked. The weeping locus was shown to be linked to three markers, but the distances (e.g., 11.4 and $17.2 \mathrm{cM}$ ) were comparatively large and hence the $p l$ gene cannot be considered "tagged." The $\mathrm{F}_{2}$ progeny were still in the juvenile phase (1-year-old) at the time the initial map was constructed, and therefore the fruit type and aphid resistance traits were not evaluated. Future efforts will be directed at investigating QTLs in relation to fruit quality, yield, and precocity within this progeny, as well as mapping QTLs controlling resistance to Sphaerotheca pannosa (Wallr.:Fr.) Lèv., Taphrina deformans (Berk.) Tul., and M. persicae in progeny from an interspecific cross, peach $\times P$. davidiana.

Other projects associated with the European Prunus Mapping Group include: 1) mapping the peach genome and identifying DNA markers linked to powdery mildew ( $S$. pannosa) resistance [at the Istituto Sperimentale per la Frutticoltura (ISF), Rome, Italy]; 2) using a cherry map to detect DNA markers for anthracnose and bacterial canker (Pseudomonas syringae pv. morsprunorum) (F. Santi, Inst. National de la Recherche Agronomique, Orleans, France; pers. comm.); and 3) mapping the cherry genome with two interspecific crosses using isoenzyme, RFLP, and RAPD markers (K. Tobutt, Horticulture Research Institute, East Malling, U.K.; pers. comm.).

\section{CULTIVAR IDENTIFICATION AND PHYLOGENETIC STUDIES}

Pedigree studies have benefited significantly by the application of molecular marker analyses in cultivation and breeding programs. For example, cultivar identification for certifying commercial germplasm, verifying plantings, recommending correct cultural practices, and protecting plant patents are important uses of DNA-based marker systems. Like MAS, this application does not depend on having a molecular linkage map. Rajapakse et al. (1995) used the presence or absence of nine RFLPs to unambiguously distinguish 34 peach scion cultivars. Bliss et al. (1994), in a preliminary survey of Prunus and apple cultivars (Malus domestica Borkh.), used RAPD markers to identify nine out of nine apricot cultivars, seven out of nine sweet cherry and plum cultivars, and 15 out of 19 almond cultivars. Researchers at the ISF have also used RAPD markers to identify peach and nectarine cultivars. In this study, six primers were used to identify 29 peach and nectarine genotypes (Quarta et al., 1994). Similarly, the European research consortium has used RAPD markers for cultivar identification in the five Prunus species it is studying (P. Arús, pers. comm.). Private nurseries have investigated the utility of DNA "profiling" as supplementary evidence to support applications for propri- 
etary plant variety registration, and although complete and unmistakable discrimination of available material was achieved, no court cases have yet been pursued (L. Darmody, pers. comm.).

Molecular markers also are useful for characterizing vegetatively propagated plant material (i.e., rootstocks) or germplasm propagated by or regenerated from tissue culture. Identification of Prunus rootstocks by DNA fingerprinting is becoming a practical necessity. In a recent study that used only six RAPD primers, Lu et al. (1996) were able to unambiguously distinguish all 18 clonal rootstocks examined, including two selections from a common parent. In addition, UPGMAcluster analysis (Sneath and Sokal, 1973) produced a dendrogram in good agreement with their putative pedigrees-findings similar to what has been reported for apple (Landry et al., 1994; Nybom, 1990), as well as for Rubus using minisatellite SSRs (Nybom and Hall, 1991; Nybom et al., 1990). Yang and Schmidt (1994) reported differentiating between an X-ray-induced mutant of cherry and the parental material using a single RAPD primer. Similarly, Hashmi et al. (1992) identified somaclonal variation for resistance to root-knot nematode [Meloidogyne incognita (Kofoid and White) Chitwood] in 'Redhaven' and 'Sunhigh' peach regenerated from in vitro culture. These regenerants were screened for RAPD markers and several primers revealed polymorphisms between regenerants and their tissue culture explant cultivar (Hashmi, 1993). This research supports the genetic basis of somaclonal variation. In summary, the application of DNA marker technology will increase as genetic transformation becomes an important component of stone fruit improvement programs (Scorza et al., 1994; Ye et al., 1994).

\section{COMPARATIVE GENE MAPPING AND FUTURE DIRECTIONS}

Following the construction of primary genetic linkage maps of Prunus species in individual laboratories, the next phase of mapping involves comparison and consolidation of maps to produce consensus maps for each crop as well as for the genus. As a result of discussions during the first international workshop on fruit tree mapping held at the Plant Genome III Conference in San Diego (Jan. 1995), RFLP probes of mapped clones have been exchanged among laboratories around the world. Peach genomic clones mapped in Clemson Univ.'s WV family were tested at MSU on the sour cherry parental cultivars Rheinische Schattenmorelle and Erdi Botermo. Fifty percent of the peach genomic clones tested so far have resulted in RFLPs. This percentage is similar to the level of polymorphism we have observed by testing WV clones in other unrelated peach progenies. These results are very encouraging for comparative mapping studies and further demonstrate the "anchoring" capability of peach RFLP markers to other Prunus species. Furthermore, the loci for two tightly linked RFLP markers, B4A9 and B7A5 in linkage group 3 of the WV map, also were linked in the sour cherry map (A. Iezzoni, pers. comm.).

Genomic and cDNA, almond RFLP probes obtained from P. Arús have been tested in the Kearneysville, WV peach cross 'Sun Crest' $x$ 'Bailey'. Fifteen percent of these clones detected polymorphism. The usefulness of these polymorphic markers for integrating the two maps is now being evaluated. Clemson Univ. WV peach clones showed a high level of polymorphism when tested in the ISF peach progeny from P. persica 'ferganensis' $x$ peach accession IF 7310828 (I. Verde, pers. comm.). In addition, the Clemson-WV peach clones are being tested in IRTA's almond and peach crosses, as well as in Prunus progenies at Univ. of California, Davis. The low copy probes from the WV family will, like clones in other laboratories, be extremely useful in identification of corresponding linkage groups in Prunus species.

As more probes are tested in diverse crosses, we will be able to combine maps and identify homologous areas and regions of translocations, insertions, deletions, etc. This information will lead to precise knowledge of common gene orders and phenotypic trait conservation, and will provide insight into the evolutionary changes that have taken place in the nuclear genome of various Prunus species. Such investigations of "synteny" in Prunus can be extended to other genera of the Rosaceae, e.g., apple (Malus spp.) and pear (Pyrus spp.). Here again, close communication and probe/primer sharing between laboratories will be essential for rapid and complete progress in such efforts.
Map-based cloning of genes, for which the protein product is not yet known, is another important area that Prunus researchers will investigate in the future. This will require detailed knowledge of the relationship between genetic (centiMorgan) and physical (base pair) distances along the chromosomes and a highly saturated linkage map flanking the trait locus. Other areas where research efforts will likely be placed in the future are 1) the use of map data to identify the chromosomal insertion site(s) in transgenic experiments, 2) the extension of efforts to map the loci of known genes (using both heterologous probes and those cloned from Prunus spp.), 3) the development of chromosome-specific marker libraries, 4) the analysis of chromosome organization in situ, and 5) the expansion of investigations into genome structure and gene expression of organellar genomes.

\section{Literature Cited}

Abbott, A., L. Belthoff, S. Rajapakse, R. Ballard, V. Baird, R. Monet, R. Scorza, P. Morgens, and A. Callahan. 1992. Development of a genetic linkage map of peach. Proc. Plant Genome I:22. (Abstr. 115)

Abbott, A., L. Eldredge, R. Ballard, V. Baird, A. Callahan, P. Morgens, and R. Scorza. 1990. Genetic mapping-Implications for variety improvement and identification. Proc. Southeast and Natl. Peach Conf., Savannah, Ga. p. 23-32.

Abbott, A., L. Eldredge, R. Ballard, V. Baird, A. Callahan, P. Morgens, and R. Scorza. 1991. Molecular genetic mapping in peaches. Proc. Southeast and Natl. Peach Conf., Hilton Head, S.C. p. 38-43.

Ahn, S. and S.D. Tanksley. 1993. Comparative linkage maps of the rice and maize genomes. Proc. Natl. Acad. Sci. USA 90:7980-7984.

Arulsekar, S., D. Parfitt, W. Beres, and E. Hanche. 1986a. Genetics of malate dehydrogenase isozymes in the peach. J. Hered. 77:49-51.

Arulsekar, S., D. Parfitt, and D. Kester. 1986b. Comparison of isozyme variability in peach and almond cultivars. J. Hered. 77:272-274.

Arús, P., R. Messeguer, M. Viruel, K. Tobutt, E. Direwanger, F. Santi, R. Quarta, and E. Ritter. 1994a. The European Prunus mapping project. Progress in the almond linkage map. Euphytica 77:97-101.

Arús, P., C. Olarte, M. Romero, and F. Vargas. 1994b. Linkage analysis of ten isozyme genes in F1 segregating almond progenies. J. Amer. Soc. Hort. Sci. 119:339-344

Baird, W.V., A.S. Estager, and J. Wells. 1994. Estimating nuclear DNA content in peach and related diploid species using laser flow cytometry and DNA hybridization. J. Amer. Soc. Hort. Sci. 119:1312-1316.

Bassam, B., G. Caetano-Annoles, and P. Gresshoff. 1991. A fast and sensitive silver-staining for DNA in polyacrylamide gels. Anal. Biochem. 196:8083.

Basten, C.J. and Z. Zeng. 1995. QTL cartographer: A suite of programs for mapping quantitative trait loci. Proc. Plant Genome III:25. (Abstr.)

Bliss, F.A., S. Arulsekar, and A.M. Dandekar. 1994. Identification of woody plant cultivars using DNA finger printing, p. 1-18. In: 1993 Research Reports, California Peaches and Nectarines. California Tree Fruit Agreement, Sacramento.

Boonprakob, U. and D.H. Byrne. 1995. Genetic relationships of diploid plums based on RAPD polymorphisms. HortScience 30:763. (Abstr. 92)

Botstein, D., R. White, M. Skolnick, and R. Davis. 1980. Construction of a genetic linkage map in man using restriction fragment length polymorphisms. Amer. J. Human Genet. 32:314-331.

Brettin, T. and A.F. Iezzoni. 1995. Chloroplast DNA polymorphisms in sweet, sour and ground cherry. HortScience 30:855. (Abstr. 922)

Caetano-Annoles, G., B. Bassam, and P. Gresshoff. 1991. DNA amplification fingerprinting using very short arbitrary oligonucleotide primers. Bio/ Technology 9:553-557.

Caetano-Anollés, G., B.J. Bassam, and P.M. Gresshoff. 1993. Enhanced detection of polymorphic DNA by multiple arbitrary amplicon profiling of endonuclease digested DNA: Identification of markers linked to the supernodulation locus in soybean. Mol. Gen. Genet. 241:57-64.

Caetano-Anollés, G. and P.M. Gresshoff. 1994. DNA amplification fingerprinting using arbitrary mini-hairpin oligonucleotide primers. Bio/Technology 12:619-623.

Chaparro, J.X., D.J. Werner, D. O’Malley, and R.R. Sederoff. 1992. Targeted mapping and linkage analysis in peach. Proc. Plant Genome I:21. (Abstr. 23)

Chaparro, J.X., D.J. Werner, D. O'Malley, and R.R. Sederoff. 1994. Targeted mapping and linkage analysis of morphological, isoenzyme, and RAPD markers in peach. Theor. Appl. Genet. 87:805-815.

Chaparro, J.X., D.J. Werner, R.W. Whetten, and D.M. O'Malley. 1995a. Inheritance, genetic interaction, and biochemical characterization of anthocyanin phenotypes in peach. J. Hered. 86:32-38.

Chaparro, J.X., D.J. Werner, R.W. Whetten, and D.M. O'Malley. 1995b. Characterization of an unstable anthocyanin phenotype and estimation of 
somatic mutation rates in peach. J. Hered. 86:186-193.

Condit, R. and S.P. Hubbell. 1991. Abundance and DNA sequence of two-base repeat regions in tropical tree genomes. Genome 34:66-71.

Dirlewanger, E. and C. Bodo. 1994. Molecular genetic mapping of peach. Euphytica 77:101-103.

Durham, R.E., G.A. Moore, and W.B. Sherman. 1987. Isozyme banding patterns and their usefulness as genetic markers in peach. J. Amer. Soc. Hort. Sci. 112:1013-1018.

Efron, B. and R. Tibshirani. 1986. Bootstrap methods for standard errors, confidence intervals, and other measures of statistical accuracy. Stat. Sci. 1:54-77.

Eldredge, L., R. Ballard, V. Baird, A. Abbott, P. Morgens, A. Callahan, R. Scorza, and R. Monet. 1992. Application of RFLP analysis to genetic linkage mapping in peaches. HortScience 27:160-163.

Excoffier, L., P.E. Smouse, and J.M. Quattro. 1992. Analysis of molecular variance inferred from metric distances among DNA haplotypes: Application to human mitochondrial DNA restriction data. Genetics 131:479-491.

Felsenstein, J. 1988. PHYLIP: Phylogenetic inference package. Univ. of Washington, Seattle.

Foolad, M.R., S. Arulsekar, V. Becerra, and F.A. Bliss. 1995. A genetic linkage map of Prunus based on an interspecific cross between peach and almond. Theor. Appl. Genet. 91:262-269.

Gogorcena, Y. and D.E. Parfitt. 1994. Evaluation of RAPD marker consistency for detection of polymorphism in apricot. Scientia Hort. 59:163-167.

Grattapaglia, D. and R. Sederoff. 1994. Genetic linkage maps of Eucalyptus grandis and Eucalyptus urophylla using a pseudo-testcross: Mapping strategy and RAPD markers. Genetics 137:1121-1137.

Gregor, D., W. Hartmann, and R. Stosser. 1994. Cultivar identification in Prunus domestica using random amplified polymorphic DNA markers. Acta Hort. 359:33-40.

Hashmi, G. 1993. Evaluation of peach regenerants, cultivars and seedlings for resistance to root-knot nematode Meloidogyne incognita. PhD Diss., Dept. of Botany, Univ. of Maryland, College Park.

Hashmi, G., F. Hammerschlag, L. Krusberg, and R. Huettel. 1992. Selection of somaclonal variants of peach for root-knot nematode resistance. J. Nematol. 24:596. (Abstr.)

Helentjaris, T., G. King, M. Slocum, D. Siedenstrang, and S. Wegman. 1985. Restriction fragment length polymorphisms as probes for plant diversity and their development as tools for applied plant breeding. Plant Mol. Biol. 5:109-118.

Hesse, C.O. 1975. Peaches, p. 285-335. In: J. Janick and J. Moore (ed.). Advances in fruit breeding. Purdue Univ. Press, West Lafayette, Ind.

Iezzoni, A., H. Schmidt, and A. Albertini. 1991. Cherries (Prunus). Acta Hort. 290:109-173

Jelenkovic, G. and E. Harrington. 1972. Morphology of the pachytene chromosomes in Prunus persica. Can. J. Genet. Cytol. 14:317-324.

Kan, Y. and A. Dozy. 1978. Antenatal diagnosis of sickle-cell anaemia by DNA analysis of amniotic-fluid cells. Lancet 2:910-912.

Kelly, J.D. 1995. Use of random amplified polymorphic DNA markers in breeding for major gene resistance to plant pathogens. HortScience 30:461465.

Knapp, S.J. 1994. Selection using molecular marker indexes, p. 1-11. In: Proceedings of the Second Symposium of the American Society for Horticultural Science and Crop Science Society of America: Analysis of Molecular Marker Data (Corvallis, Ore.). Amer. Soc. Hort. Sci., Alexandria, Va.

Landry, B.S., R.Q. Li, W.Y. Cheung, and R.L. Granger. 1994. Phylogeny analysis of 25 apple rootstocks using RAPD markers and tactical gene tagging. Theor. Appl. Genet. 89:847-852.

Lincoln, S., M. Daly, and E. Lander. 1992a. Mapping genes controlling quantitative traits with MAPMAKER/QTL 1.1. 2nd ed. Whitehead Inst. Tech. Rpt., Cambridge, Mass.

Lincoln, S., M. Daly, and E. Lander. 1992b. Constructing genetic maps with MAPMAKER/EXP 3.0. 3rd ed. Whitehead Inst. Tech. Rpt., Cambridge, Mass.

Litt, M. and J. Luty. 1989. A hypervariable microsatellite revealed by in vitro amplification of a dinucleotide repeat within the cardiac muscle actin gene. Amer. J. Human Genet. 44:397-401.

Liu, B.H. and S.J. Knapp. 1990. GMENDEL: A program for Mendelian segregation and linkage analysis of individual or multiple progeny populations using log-likelihood ratios. J. Hered. 81:407.

Lu, Y. and B.H. Liu. 1995. A new computer package for genomic research: PGRI. Proc. Plant Genome III:60. (Abstr. P151)

Lu, Z.-X., G.L. Reighard, W.V. Baird, A.G. Abbott, and S. Rajapakse. 1996. Identification of peach rootstock cultivars by RAPD markers. HortScience 31:127-129.

Mantel, N. 1967. The detection of disease clustering and a generalized regression approach. Cancer Res. 27:209-220.

Mehlenbacher, S.A. 1995. Classical and molecular approaches to breeding fruit and nut crops for disease resistance. HortScience 30:466-477.

Mehlenbacher, S.A., V. Cociu, and L.F. Hough. 1991. Apricots (Prunus). Acta Hort. 290:63-107.

Melchinger, A.E. 1990. Use of molecular markers in breeding for oligogenic disease resistance. Plant Breeding 104:1-19.

Michelmore, R.W., I. Paran, and R.V. Kesseli. 1991. Identification of markers linked to disease-resistance genes by bulked segregant analysis: A rapid method to detect markers in specific genomic regions by using segregating populations. Proc. Natl. Acad. Sci. USA 88:9828-9832.

Monet, R. 1989. Peach genetics: Past, present and future. Acta Hort. 254:49 57.

Monet, R., Y. Bastard, and B. Gibault. 1985. Etude genetique et amelioration des peches plates. Agronomie 5:727-731.

Mowrey, B.D., D.J. Werner, and D.H. Byrne. 1990. Inheritance of isocitrate dehydrogenase, malate dehydrogenase, and shikimate dehydrogenase in peach and peach X almond hybrids. J. Amer. Soc. Hort. Sci. 115:312-319.

Mullis, K.B., F. Faloona, S. Scharf, R. Saiki, G. Horn, and H. Erlich. 1986. Specific enzymatic amplification of DNA in vitro: The polymerase chain reaction. Cold Spring Harbor Symp. Quantitative Biol. 51:263-273.

Nei, M. and W. Li. 1979. Mathematical model for studying genetic variance in terms of restriction endonucleases. Proc. Natl. Acad. Sci. USA 76:52565273.

Nodari, R.O., E.M. Koinange, J.D. Kelly, and P. Gepts. 1992. Towards an integrated linkage map of common bean. I. Development of genomic DNA probes and levels of restriction fragment length polymorphism. Theor. Appl. Genet. 84:186-192.

Nybom, H. 1990. Genetic variation in ornamental apple trees and their seedlings (Malus, Rosaceae) revealed by DNA 'fingerprinting'. Hereditas 113:17-28.

Nybom, H. and H. Hall. 1991. Minisatellite DNA 'fingerprints' can distinguish Rubus cultivars and estimate their degree of relatedness. Euphytica 53:107114.

Nybom, H., S. Rogstad, and B. Schall. 1990. Genetic variation detected by use of the M13 "DNA fingerprint" probe in Malus, Prunus, and Rubus (Rosaceae). Theor. Appl. Genet. 79:153-156.

Olson, M., L. Hood, C. Cantor, and D. Botstein. 1989. A common language for physical mapping of the human genome. Science 245:1434-1435.

Paran, I. and R.W. Michelmore. 1993. Development of reliable PCR-based markers linked to downy mildew resistance genes in lettuce. Theor. Appl. Genet. 85:895-903.

Paterson, A., J. DeVerna, B. Lanini, and S. Tanksley. 1990. Fine mapping of quantitative trait loci using selected overlapping recombinant chromosomes, in an interspecies cross of tomato. Genetics 124:735-742.

Powell, W., M. Morgante, C. Andre, M. Hanafey, J. Vogel, S. Tingey, and A. Rafalski. 1996. Comparison of RFLP, RAPD, AFLP and SSR (microsatellite) markers for germplasm improvement. Molecular Breeding (In press.)

Quarta, R., M. Dettori, I. Verde, P. Laino, F. Santucci, A. Vantaggi, and S. Sabatini. 1994. Analisi della variabilità genetica in germoplasma di Pesco mediante marcatori molecolari, p. 73-82. In: S. Sansavini and M. Pancaldi (eds.). Agro bio frut su: Tecnologie Avanzate perl'identificazione Varietale e il Controllo Sanitario nel Vivaismo Fruttiviticolo. Agro-Bio-Frut-Cesena 6 May 1994.

Ragot, M. and D.A. Hoisington. 1993. Molecular markers for plant breeding: Comparisons of RFLP and RAPD genotyping costs. Theor. Appl. Genet. 86:975-984.

Rajapakse, S., L.E. Belthoff, G. He, A.E. Estager, R. Scorza, I. Verde, R.E. Ballard, W.V. Baird, A. Callahan, R. Monet, and A.G. Abbott. 1995. Genetic linkage mapping in peach using morphological, RFLP and RAPD markers. Theor. Appl. Genet. 90:503-510.

Ramming, D.W. and V. Cociu. 1991. Plums (Prunus). Acta Hort. 290:233287.

Rangwen, R., M.S. Akkaya, A.A. Bhagwar, U. Lavi, and P.B. Cregan. 1995. The use of microsatellite DNA markers for soybean genotype identification. Theor. Appl. Genet. 90:43-48.

Ritter, E., C. Gerbhardt, and F. Salamini. 1990. Estimation of recombination frequencies and construction of RFLP linkage maps in plants from crosses between heterozygous parents. Genetics 125:645-654

Rohlf, F.J. 1992. NTSYS-pc: Numerical taxonomy and multivariate analysis system, version 1.7. Applied Biostatistics, Setauket, N.Y.

Saiki, R.K., S. Scarf, F. Falloona, K. Mullis, G. Horn, H.A. Erlich, and N. Arnheim. 1985. Enzymatic amplification of beta-globulin genomic sequences and restriction analysis for diagnosis of sickle cell anemia. Science 230:1350-1354.

Santos, J.B.D., J. Nienhuis, P. Skrouch, and M.K. Slocum. 1994. Comparison of RAPD and RFLP genetic markers in determining genetic similarity among Brassica oleracea L. genotypes. Theor. Appl. Genet. 87:909-915.

SAS Institute. 1990. SAS/STAT user's guide. SAS Inst., Cary, N.C.

Schery, R.W. 1972. Plants for man. Prentice Hall, Englewood Cliffs, N.J

Scorza, R., A. Mehlenbacher, and G. Lightner. 1985. Inbreeding and coancestry 
of freestone peach cultivars of the eastern United States and implications for peach germplasm improvement. J. Amer. Soc. Hort. Sci. 110:547-552.

Scorza, R., M. Ravelonardo, A.M. Callahan, J. Cordts, M. Fuchs, J. Dunez, and D. Gonsalves. 1994. Transgenic plums (Prunus domestica L.) express the plum pox virus coat protein gene. Plant Cell Rpts. 14:18-22.

Shi, J., D.G. Heckel, and M.R. Goldsmith. 1995. A genetic linkage map for the domesticated silkworm, Bombyx mori, based on restriction fragment length polymorphism. Genet. Res. 66:109-126.

Shimada, T., T. Haji, Y. Masami, T. Takeda, K. Nomura, and M. Yoshida. 1994. Classification of mume (Prunus mume Sied. et Zucc.) by RAPD assay. J. Jpn. Soc. Hort. Sci. 63:543-551.

Sneath, P.H. and R.R. Sokal. 1973. Numerical taxonomy: The principles and practice of numerical classification. W.H. Freeman and Co., San Francisco.

Stam, P. 1993. Construction of integrated genetic linkage maps by means of a new computer package: JOINMAP. Plant J. 3:739-744.

Stockinger, E.J., C.A. Mulinix, C.M. Long, T.S. Brettin, and A.F. Iezzoni. 1996. A linkage map of sweet cherry based on RAPD analysis of a microspore-derived callus culture population. J. Hered. 87:214-218.

Suiter, K.A., J.F. Wendell, and J.S. Case. 1983. Linkage-1: A PASCAL computer program for the detection and analysis of genetic linkage. J. Hered. 74:203-204.

Swofford, D.L. 1991. PAUP: Phylogenetic analysis using parsimony. version 3.1. Illinois Natural History Survey, Champaign.

Thormann, C.E., M. Ferreira, L. Camargo, J. Tivang, and T.C. Osborn. 1994 Comparison of RFLP and RAPD markers to estimating genetic relationships within and among cruciferous species. Theor. Appl. Genet. 88:973980.

Tragoonrung, S., V. Kanazin, P.M. Hayes, and T.K. Blake. 1992. Sequencetagged-site-facilitated PCR for barley genome mapping. Theor. Appl. Genet. 84:1002-1008

U.S. Dept. of Agriculture. 1993. Agricultural statistics. U.S. Government Printing Office, Washington, D.C.

Viruel, M.A., R. Messeguer, M.C.D. Vicente, J. Garcia-Mas, P. Puidomènech, F. Vargas, and P. Arús. 1995. A linkage map with RFLP and isozyme markers for almond. Theor. Appl. Genet. 91:964-971.

Vogel, J.M., A. Rafalski, W. Powell, M. Morgante, C. Andre, M. Hanafey, and
S.V. Tingey. 1996. Application of genetic diagnostics to plant genome analysis and plant breeding. HortScience 31:1106-1107.

Vos, P., R. Hogers, M. Bleeker, M. Reijans, T. van de Lee, M. Hornes, A. Frijters, J. Pot, J. Peleman, M. Kuiper, and M. Zabeau. 1995. AFLP: A new technique for DNA fingerprinting. Nucleic Acids Res. 23:4407-4414.

Vowden, C., M. Ridout, and K.R. Tobutt. 1995. LINKEM. A program for genetic linkage analysis. J. Hered. 86:249-250.

Warburton, M.L. and F. Bliss. 1995. Placement of economically important loci on an existing linkage map in peach. Proc. Plant Genome III:85. (Abstr. P250)

Weber, J.L. and P.E. May. 1989. Abundant class of human DNA polymorphisms which can be typed using the polymerase chain reaction. Amer. J. Human Genet. 44:388-396.

Weeden, N.F., G.M. Timmerman, M. Hemmat, B. Kneen, and M. Lodhi. 1992. Inheritance and reliability of RAPD markers. Crop Sci. Soc. Amer., Amer. Soc. Hort. Sci., and Amer. Genet. Assoc., Minneapolis, Minn. p. 12-17.

Welsh, J. and M. McClelland. 1990. Fingerprinting genomes using PCR with arbitrary primers. Nucleic Acids Res. 18:7213-7218.

Wilkinson, L. 1989. SYSTAT: The system for statistics. SYSTAT, Evanston, Ill.

Williams, J.G.K., A.R. Kubelik, K.J. Livak, J.A. Rafalski, and S.V. Tingey. 1990. DNA polymorphisms amplified by arbitrary primers are useful as genetic markers. Nucleic Acids Res. 18:6531-6535.

Wyman, A. and R. White. 1980. A highly polymorphic locus in human DNA. Proc. Natl. Acad. Sci. USA 77:6754-6758.

Yamazaki, K., M. Okabe, and E. Takahashi. 1987. Inheritance of some characteristics and breeding of new hybrids in flowering peaches. Bul. Kanagawa Hort. Expt. 34:46-53.

Yang, H. and H. Schmidt. 1994. Selection of a mutant from adventitious shoots formed in X-ray treated leaves and differentiation of standard from mutant with RAPDs, p. 287-290. In: H. Schmidt and M. Kellerhals (eds.). Progress in temperate fruit breeding. Kluwer Academic Publishers, Dordrecht, The Netherlands.

Ye, X., S. Brown, R. Scorza, J. Cordts, and J. Sanford. 1994. Genetic transformation of peach tissue by particle bombardment. J. Amer. Soc. Hort. Sci. 119:367-373. 


\title{
Application of Genetic Diagnostics to Plant Genome Analysis and Plant Breeding
}

\author{
J.M. Vogel and A. Rafalski \\ Biotechnology Research, Agricultural Products, E.I. DuPont, P.O. Box 80402, Wilmington, DE 19880-0402 \\ W. Powell \\ Scottish Crop Research Institute, Invergowrie, Dundee, DD2 5DA Scotland, U.K. \\ M. Morgante \\ Universita di Udine, Departimento di Produzione Vegetale, Via delle Scienze 208, Udine I-33100, Italy \\ C. Andre, M. Hanafey, and S.V. Tingey \\ Biotechnology Research, Agricultural Products, E.I. DuPont, P.O. Box 80402, Wilmington, DE 19880-0402
}

A variety of marker systems has been developed over the years to
facilitate the analysis of complex plant and animal genomes. Detailed
genome investigation using classical genetic phenotypes and isozymes,
the first genetic markers, pose severe limitations, including problems
with phenotypic penetrance or heritability, difficulties involved with
constructing multiply marked lines, and low map resolution. DNA-
based marker systems circumvent many of these problems. Based
solely on nucleotide sequence polymorphism, DNA markers are
potentially limitless in number and their identification and use are
unaffected by phenotype.

Restriction fragment length polymorphisms (RFLPs) are codominant DNA markers that have been applied to a wide range of species, but their effective use has been limited by the large amount of genetic material required and the labor involved in the analysis. Alternative methods based on the polymerase chain reaction (PCR) are technically less demanding and offer greater experimental simplicity. For example, the random amplified polymorphic DNA (RAPD) assay (William et al., 1990, 1993) can identify extremely large numbers of genomic polymorphisms, requires minimal amounts of input DNA, and is technically simple and straightforward; their disadvantage is their dominance, as homozygous dominant genotypes cannot be distinguished from heterozygotes. Simple sequence repeats (SSR), or microsatellites, are abundant, well-dispersed, and highly polymorphic in many plant genomes and offer a codominant, PCR-based marker system (Akkaya et al., 1992; Lynn Senior and Huen, 1993; Morgante and Olivieri, 1993). Multiplexed genome assay methods, such as amplified fragment length polymorphism (AFLP) (Zabeau and Vos, 1993), inter-repeat amplification (Zietkiewicz et al., 1994), and selective amplification of microsatellite polymorphic loci (SAMPL) (Vogel and Morgante, unpublished data), can reveal several polymorphisms simultaneously. These multiplexed methods are becoming increasingly useful for fingerprinting, cultivar identification, marker discovery, and mapping.

The choice of marker system to use for a particular application will depend somewhat on its ease of use and on the technical expertise of the investigator; however, the most important consideration is the type of genomic information required. Each method makes an estimate of genomic polymorphism and identifies polymorphic markers in its own distinct way, and each has different inherent biases (Rafalski et al., 1995). These marker systems differ in their capacity to detect polymorphisms in a given population (informativeness) and in the number of loci that can be simultaneously detected per experiment (multiplex ratio). Although all these methods have been applied separately toward analysis of individual genomes or populations, we know of no case whereby all have been directly applied to a common set of individuals. Below we describe the results of a direct comparison of these assay methods on a set of 12 soybean [Glycine max (L.) Merr.] genotypes.

Received for publication 29 Nov. 1995. Accepted for publication 29 Jan. 1996. The cost of publishing this paper was defrayed in part by the payment of page charges. Under postal regulations, this paper therefore must be hereby marked advertisement solely to indicate this fact.
An initial RFLP survey of soybean germplasm, together with coancestry (pedigree) information, allowed the identification of 12 soybean genotypes that collectively account for $92 \%$ of the allelic variation in the gene pool of North American soybean cultivars (Delanney et al., 1983). Genetic material from these 12 genotypes, which include 10 cultivars and two Glycine soja Sieb. \& Zucc. accessions, was used as a template for four distinct genome assays. A previous RFLP analysis (Rafalski and Tingey, 1993) had identified 110 RFLP loci that were polymorphic between two of these 12 lines. Using conventional Southern blotting and probe hybridization, these RFLP loci were assayed for polymorphism in the entire set of 12 lines. Similarly, this set of 12 genotypes was assayed with RAPDs using PCR with 52 different random 10 mers and also with primer pairs representing 36 soybean SSR loci (AG, AC, and AT repeat sequences all represented). DNA from these 12 genotypes also was used as template for a multiplexed AFLP analysis with two restriction enzyme combinations and seven primer combinations.

A marker (i.e., locus, probe, or band on a gel) was scored as polymorphic if at least two alleles (either dominant or codominant) could be identified among the set of the 12 cultivars. Because of the RFLP probe preselection conditions (previously identified polymorphism between the cultivar Bonus and the PI81762 accession), all 110 RFLP loci were classified as polymorphic; however, previous data had revealed that only $\approx 25 \%$ of arbitrarily chosen RFLP probes identify a polymorphism in the soybean genome. Eighty-one polymorphic bands could be scored from the 52 RAPD primer reactions. All 36 SSR loci were polymorphic, and 136 of the 337 (40\%) AFLP bands could be scored as polymorphic.

These raw data were then used to estimate the expected heterozygosity and effective multiplex ratio for each marker system (Table 1). The practical utility of a marker system depends on both of these values; that is, a marker's utility is essentially a balance of the polymorphism revealed by a single reaction with the degree to which a single reaction or experiment can detect multiple polymorphisms. A reasonable estimate of marker utility, therefore, is essentially a product of information content and multiplex ratio.

Table 1. DNA markers in soybean.

\begin{tabular}{lccc}
\hline \hline $\begin{array}{l}\text { Marker } \\
\text { system }\end{array}$ & $\begin{array}{c}\text { Effective } \\
\text { multiplex ratio }\end{array}$ & $\begin{array}{c}\text { Expected } \\
\text { heterozygosity }\end{array}$ & $\begin{array}{c}\text { Marker index } \\
\text { (marker utility) }^{\mathrm{x}}\end{array}$ \\
\hline RFLP & 0.25 & 0.41 & 0.10 \\
RAPD & 1.56 & 0.31 & 0.48 \\
SSR & 1.0 & 0.60 & 0.60 \\
AFLP & 19.2 & 0.32 & 6.14 \\
\hline
\end{tabular}

${ }^{2}$ The number of products from a single amplification reaction multiplied by the fraction of the products that are polymorphic.

yA measure of a marker's information content. Expected heterozygosity, H, equals $1-\Sigma \mathrm{p}_{\mathrm{i}}^{2}$, where $\mathrm{p}_{\mathrm{i}}$ is the allele frequency for the ith allele. For this calculation, only the polymorphic bands from each reaction were considered. ${ }^{\mathrm{x}} \mathrm{A}$ product of effective multiplex ratio and expected heterozygosity. 


\section{Literature Cited}

Akkaya, M., A.A. Bhagwat, and P.B. Cregan. 1992. Length polymorphisms of simple sequence repeat DNA in soybean. Genetics 132:1131-1139.

Delanney, X., D.M. Rodgers, and R.G. Palmer. 1983. Relative genetic contributions among ancestral lines to North American soybean cultivars. Crop Sci. 23:183-189.

Lynn Senior, M. and M. Heun. 1993. Mapping maize microsatellites and polymerase chain reaction confirmation of the targeted repeats using a CT primer. Genome 36:884-889.

Morgante, M. and A.M. Olivieri. 1993. PCR-amplified microsatellites as markers in plant genetics. Plant J. 3:175-182.

Rafalski, A. and S. Tingey. 1993. RFLP map of soybean (Glycine max) $2 \mathrm{~N}=$ 40, p. 6.149-6.156. In: S.J. O'Brien (ed.). Genetic maps, locus maps of complex genomes. 6th ed. Cold Spring Harbor Lab. Press, Cold Spring Harbor, N.Y.
Rafalski, J.A., J. Vogel, M. Morgante, W. Powell, and S.V. Tingey. 1996. Generating and using DNA markers in plants. In: E. Lai and B. Birren (eds.). Analysis of non-mammalian genomes-A practical approach. Academic, Orlando, Fla. (In press.)

Williams, J.G.K., A.R. Kubelik, K.S. Livak, J.A. Rafalski, and S.V. Tingey. 1990. DNA polymorphisms amplified by arbitrary primers are useful as genetic markers. Nucleic Acids Res. 18:6531-6535.

Williams, J.G.K., M.K. Hanafey, J.A. Rafalski, and S.V. Tingey. 1993. Genetic analysis using RAPD markers, p. 704-740. In: R. Wu (ed.). Methods in enzymology. vol. 218. Academic, Orlando, Fla.

Zabeau, M. and P. Vos. 1993. Selective restriction fragment amplification: A general method for DNA fingerprinting. European Patent 92402629.7 (Publ. 0534858 A1).

Zietkiewicz, E., A. Rafalski, and D. Labuda. 1994. Genome fingerprinting by simple sequence repeat (SSR)-anchored polymerase chain reaction amplification. Genomics 20:176-183.

\title{
Progress of Apple Genetic Mapping in Europe
}

\author{
Graham J. King \\ Breeding and Genetics Department, Horticulture Research International, Wellesbourne, Warwick CV35 9EF, U.K.
}

The European Apple Genome Mapping Project (EAGMAP) is acting as a focus for interdisciplinary studies relating to the genetics of Malus. Five replicated reference populations have been distributed to seven sites in Europe and are being used to collate a wide range of phenotypic and genotypic records. Isozyme loci, restriction fragment length polymorphisms (RFLPs), random amplified polymorphic DNA (RAPDs), and other DNA markers are being used to construct a unified genetic linkage map. The linkage maps being constructed have markers in common with U.S. and New Zealand Malus maps, as well as Prunus maps. Genotypic and phenotypic measurements have been precisely defined and standardized amongst participants. Phenotypic measurements for many agronomic traits are being replicated in various geographical locations over several years. To determine which agronomic traits are amenable to genetic analysis, analytical methodologies are being developed to maximize genetic linkage information from diverse types of segregation data in an outbreeding species before quantitative trait analysis. The segregation of fungal and insect resistance genes, tree habit, juvenility, budbreak, and many fruit characters has been scored. Markers have been identified that are linked to and flank scab (Venturia inaequalis Cke. Wint.) and mildew (Podosphaera leucotricha Ell. and Ev.) resistance genes. A relational database and object-oriented application, APPLE-STORE, has been developed for combined management of genotypic and phenotypic data. Studies are being carried out to quantify the sensory properties and preferences of apple fruit to establish a link with genetic analyses. Related studies that quantify the economic and social effects of apple production aim to provide apple breeders with a range of decision-making tools for future cultivar selection.

Received for publication 29 Nov. 1996. Accepted for publication 25 Jan. 1996 The Development of the European Apple Crop Project is funded by the Commission of the European Communities from the AIR-3 program (CT920473), with matching funding provided from national ministries of agriculture, research councils, and the Swiss National Science Foundation. I am grateful to all participants in this project, both past and present, at the following institutions: Horticulture Research International, Wellesbourne, U.K.; East Malling Research Station, U.K.; Centre for Plant Breeding Research (CPRODLO), Wageningen, The Netherlands; Federal Centre for Breeding Research on Cultivated Plants, Institute for Breeding of Ornamental Plants, Ahrensburg, Germany; Institut National de la Recherche Agronomique, Angers, France; Pomology Institute, Naoussa, Greece; Dipartimento di Coltivazione Arboree, University of Bologna, Italy; Swiss Federal Institute of Technology, Zurich, Switzerland; Swiss Federal Research Station for Fruit-Growing, Viticulture and Horticulture, Wädenswil, Switzerland; Katholieke Universiteit, Leuven, Belgium; Scottish Agricultural College, Edinburgh, U.K.; and Institute of Food Research, Reading, U.K. The cost of publishing this paper was defrayed in part by the payment of page charges. Under postal regulations, this paper therefore must be hereby marked advertisement solely to indicate this fact.

\section{PROCEDURES}

Apple (Malus $\times$ domestica Borkh.) is one of the most widely grown of the fruit crops, and the crop in Europe represents $\approx 20 \%$ of world production. Existing production is served by a relatively small number of varieties, most of which are not the product of modern breeding programs. However, there is increasing demand for modern varieties that suit the needs of producer, retailer, and consumer.

Much progress has been made in understanding the genetics of apple (Alston and Watkins, 1975; Brown, 1992; Korban and Chen, 1992). The advent of molecular markers, led by isozyme studies (Alston and Batlle, 1992; Chevreau and Laurens, 1987; Manganaris and Alston, 1987), has accelerated the rate and resolution of such knowledge, and is expected to have a profound effect on future breeding strategies.

The EAGMAP (King, 1994; King et al., 1991) was initiated in 1989 to increase understanding of the genetics of apple. The strategy adopted was to generate a series of segregating reference populations that could be vegetatively propagated and distributed to institutions throughout Europe. Over a period of years, complementary genotypic data are being accumulated to construct genetic linkage maps from isozymes, RFLPs, RAPDs, and other DNA markers. Phenotypic data are being recorded for a wide range of agronomic characters over several years in diverse geographic regions. All experimental data are collated in a central database. Related studies have been initiated that focus on aspects of fruit quality and on the economic and social aspects of apple production.

\section{Mapping populations}

Five reference populations (Table 1) were generated from crosses carried out during 1989. These were germinated and maintained in nursery conditions before vegetative propagation. Up to six replications were generated by grafting on to M27 dwarfing rootstock. Trees were distributed to seven sites throughout Europe in Spring 1993. The plantations cover $13^{\circ}$ of latitude from Naoussa in Greece $\left(40.5^{\circ} \mathrm{N}\right)$ to Ahrensburg in Germany $\left(53.5^{\circ} \mathrm{N}\right)$.

During this exercise, logistical problems were solved. The solutions have been incorporated into subsequent trials. It was absolutely vital to ensure accurate labeling and recording of individual trees and plot positions. The effect of outcrossing to unknown parents due to pollen contamination has been severe in some populations. In addition, the effects of graft incompatibility of some genotypes on the M27 rootstock became apparent 9 months following bud-grafting. These problems initially reduced the number of replications available for some populations, but has since been remedied by further propagation. 
Table 1. Reference populations used for genetic studies in the European Apple Genome Mapping Project.

\begin{tabular}{lllcc}
\hline \hline Code & \multicolumn{1}{c}{$\begin{array}{c}\text { Female } \\
\text { parent }\end{array}$} & $\begin{array}{c}\text { Male } \\
\text { parent }\end{array}$ & $\begin{array}{c}\text { No. } \\
\text { progeny }\end{array}$ & $\begin{array}{c}\text { Total trees } \\
\text { in field }\end{array}$ \\
\hline $\mathrm{J}$ & Prima & Fiesta & 159 & 1068 \\
$\mathrm{R}$ & Fiesta & 3762 & 164 & 887 \\
$\mathrm{Y}$ & Fiesta & SA572/2 & 184 & 862 \\
$\mathrm{P}$ & Double Red & SA572/2 & 133 & 493 \\
$\mathrm{G}$ & Northern Spy & & & \\
$\mathrm{G}$ & Crimson Spy & 3762 & 144 & 576 \\
\hline
\end{tabular}

${ }^{2} 3762$ is derived from open-pollinated Malus robusta, while SA572/2 is an advanced columnar selection with scab and mildew resistance, bred by $\mathrm{K}$. Tobutt at East Malling.

\section{Strategy for linkage mapping}

Preliminary studies at Horticulture Research International (HRI) indicated a high degree of polymorphism in the " $R$ " family due to the distinct origin of the $M$. robusta (Carr.) Rehd. genotype. However, as a result of the greater number of replications available, and the lower proportion of "outcross" individuals, the "J" population was adopted as the core mapping population in 1993. This population derives from the apple varieties Fiesta and Prima and has a low level of genotypic polymorphism. The frequency at which polymorphic DNA markers have been discovered has, therefore, been lower than originally expected. However, by adopting this strategy, it is now apparent that mapping the $\mathbf{J}$ alleles in subsequent populations is easy. In addition, it should be easy to exploit the marker alleles in breeding populations, thereby minimizing difficulties encountered with other species where linkage maps have been based on "wide" crosses. A saturated linkage map is being generated for the J population, with well-spaced selected markers from each of the 17 linkage groups subsequently being mapped in the R population, followed by the "Y" population. Mapping within the remaining two populations is likely to occur in response to the need to map particular agronomic traits and may focus on particular linkage groups.

Where possible, isozyme loci are being mapped in the populations. Isozymes are valuable in their ability to provide codominant information that may readily be compared between research groups, as well as between genera (e.g. Malus and Prunus). Isozyme data have also been useful in rapidly identifying possible outcross contaminants within the mapping populations. Candidate contaminants may then be confirmed by screening with a larger number of DNA RAPD alleles.

RAPD markers have provided the early framework for the mapping studies. The screening process for identifying informative markers was intensive for the J mapping population and involved assessing more than 1000 primers. Given the problems associated with reproducing RAPD markers in different laboratories, particularly stringent criteria were established within this project. Thus, only RAPD fragments of relatively high intensity, which were demonstrably reproducible and preferably flanked in the gel track by nonsegregating fragments, were accepted (King, 1994). This procedure has enabled participating laboratories to exchange information and reproduce results on complementary subsets of mapping populations. Unfortunately, many RAPD markers reported to have been mapped in Malus by the Cornell group (Hemmat et al., 1994) have proven difficult to reproduce in the European laboratories, possibly due to the different criteria used for accepting a marker fragment and to differences in PCR amplification conditions.

The accumulation of RFLP markers was initially hindered by the lack of polymorphic probes. Early work concentrated on establishment of small genomic DNA libraries, each derived from fragments generated by different restriction enzymes. The probes generated from these libraries tended to represent either a high proportion of repeated sequences or nonpolymorphic low-copy sequences. However, the more recent use of a leaf cDNA library has proven to be extremely productive, with a high proportion of informative probes. In addition, probes derived from several other sources are being mapped. These include cDNAs mapped in the New Zealand program (Gardiner et al., 1994) and Cornell program (Hemmat et al., 1994). Over 30 Malus gene sequences are now present in the European Molecular Biology Labo- ratory DNA database (Release 42), and some of these are also being mapped. There is interest in the cosegregation of genes involved in fruit ripening (ethylene synthesis) and fruit quality characters. In addition, some cDNA and genomic probes that have been mapped in almond (Prunus amygdalus (Batsch)) (Arus et al., 1994) give clear hybridization signals in Malus and are being mapped in the reference populations. This procedure will enable detailed study of the synteny of linkage groups within the Rosaceae between Malus and Prunus.

\section{Phenotypic assessments}

The assessment of phenotype for genetic studies has proven to be one of the most demanding aspects of the mapping project. Due to the dispersed nature of the experiments and collection of records over several years, great care is required in design, record taking, and management of data. Following the preliminary assessments of the populations in 1993, it became apparent that clearly defined descriptors were essential if data were to be collated before genetic analysis. A protocol that ensures adequate experimental details are recorded has been developed, and any deviation from an established descriptor is noted. Where possible, scales have been clarified and simplified. An important aspect in devising descriptors has been to encourage separate scoring for the putative components of compound measures, each of which may be determined by unlinked genes.

Among the range of characters that have been scored to date (Table 2 ), some segregate in all populations, while others derive from a particular parent genotype.

\section{Data management}

The requirements for data management for this multi-site, interdisciplinary project are being met by a relational database design, implemented with an object-oriented graphical user interface. The APPLE-STORE design has been developed by Gina Hyne at HRI to combine genotypic and phenotypic data relating to the reference populations and varieties, as well as information relating to molecular markers, associated bibliographic references, and colleagues. Data relating to each area of activity are held in a series on tables connected by defined and unambiguous relationships. The relational design is modular, and its key features of manipulating data relating to individual plants and pedigrees has allowed the design to be adapted readily for use in a breeding program and for other species. The APPLE-STORE application has been implemented in Microsoft Access version 2.0 for Windows and comprises forms and reports based on one or more queries that gather data from one or many tables. The forms provide the interface between the user and the tables of data. The database is also being extended for related studies. "CORE-STORE for Malus" is currently being developed to manage genetic resource data and will enable functional links to be made between genetic resources, genetic studies, and breeding populations.

Table 2. Range of phenotypic traits being scored, with defined descriptors in replicated experiments, on the reference populations within the European Apple Genome Mapping Project.

\begin{tabular}{lr}
\hline $\begin{array}{l}\text { Resistance and } \\
\text { morphological } \\
\text { traits }\end{array}$ & $\begin{array}{c}\text { No. } \\
\text { descriptor }\end{array}$ \\
\hline Resistance to & 2 \\
$\quad$ Aphis pomi Degeer (apple aphid) & 2 \\
Dysaphis devecta Walker (rosy leaf curling aphid) & 4 \\
Dysaphis plantaginea Passerini (rosy apple aphid) & 1 \\
Eriosoma lanigerum Hausmann (woolly apple aphid) & 13 \\
Podosphaera leucotricha Ell. and Ev. (mildew) & 9 \\
Venturia inaequalis Cke. Wint. (scab) & 1 \\
Nectria galligena Bres. (canker) & \\
Morphological & 3 \\
Apical shoot & 3 \\
Feathering & 5 \\
Flowering & 20 \\
Fruit & 14 \\
Tree development & 3 \\
Leaf & \\
\hline
\end{tabular}




\section{Data analysis}

To make full use of the diverse types of molecular marker data generated, techniques are being developed by $\mathrm{C}$. Maliepaard at the Centre for Plant Breeding Research (CPRO-DLO), Wageningen, The Netherlands, which specifically address the segregation types within outcrossing heterozygous populations. For RAPDs, two types of informative segregation occur: $F_{2}$ (3:1) and backcross (1:1). With RFLPs, up to six types of segregation patterns may occur. Modifications to the JoinMap software (Stam, 1993) are being made to combine these differing segregation types to produce cohesive linkage maps. Interval mapping method is one of the methods often used for mapping quantitative trait loci (QTLs) using molecular markers (Lander and Botstein, 1989). In a full-sib family of an outcrossing species such as apple, the markers flanking a QTL are not necessarily the most informative ones. Simulation studies by Maliepaard and Van Ooijen (1996) show that neighboring markers may compensate for missing information. Discontinuities in the graph of the test statistic can be removed and QTLs can be detected that would not have been found if only flanking markers had been considered.

The disparate sets of phenotypic data being accumulated provide a challenge in determining which characters are amenable to genetic analysis. A range of exploratory data analysis and multivariate analysis techniques are being employed to evaluate the various sets of data.

\section{RESULTS}

\section{Genotype and linkage}

The choice of relatively closely related germplasm for mapping purposes has limited the likelihood of detecting informative markers. However, those marker loci that are mapped are likely to provide highly variable alleles in existing breeding stocks and genetic resource collections. Of the 239 marker loci mapped by early $1995,15 \%$ are in common with, or have been distributed to, other mapping projects. This connectivity is a healthy aspect of fruit genetic mapping, which should avoid the wasteful effects of duplication encountered with other crops such as Brassica, where short-term commercial interests have hindered global genetic studies.

A consensus European apple linkage map is being prepared and will be published. Linkage has been established with several major gene effects to date. In addition to markers linked with the $V f$ scab resistance, Markussen et al. (1995) have recently identified RAPD markers linked to the $P l l$ source of mildew resistance, which is derived from Malus robusta.

The use of the bulked segregant approach to identify markers linked to major gene effects has been well exploited in mapping introgressed fungal resistances in Malus. Yang and Kruger (1994) were the first to report close linkage of a RAPD marker to the $V f$ source of scab resistance. Further RAPD markers have subsequently been identified by Koller et al. (1994). Together with demonstration of linkage with the isozyme locus PGM-1 (Manganaris et al., 1994), these markers are enabling a detailed picture to emerge of the region of chromosome derived from Malus floribunda Crandell 821, which confers $V f$ resistance. The RAPD markers linked to $V f$ are now being converted to more stable sequence characterized amplified regions (SCARs) and codominant characterized amplified polymorphic sequences (CAPS) assays. In addition, an RFLP probe derived from one of the cloned RAPD markers allows accurate mapping of the locus within and between the mapping populations. A further RFLP locus closely linked to the resistance locus has been identified by routine mapping with random cDNAs.

Progress within the next 2 years is expected to provide a wealth of detailed genetic information that will be related not only to major sources of resistance, but also to juvenility, flowering time, and fruit characters.

\section{Phenotypic information}

The data sets amassed to date are providing some initial insight into which characters are amenable to further genetic analysis. Compari- son of data across sites enables an assessment of genotype $\times$ environment interactions and heritability.

The expression of variation in the juvenile phase, which is of importance to apple production, breeding, and genetic studies, is being well documented in these studies. The range of variation is ensured by the inclusion of parental genotypes that are reported to confer a juvenile phase from as short as 3 years (Malus robusta 3762 ) to as long as 12 years ('Northern Spy' derivatives). Although this experiment is only partially completed, it is apparent from records obtained from the various sites that this trait has a high degree of heritability.

The benefits of accumulating data over several years are becoming apparent. The difficulties in ensuring appropriate conditions for disease development, inoculum buildup, and fruit yield are being overcome by experiments replicated spatially and temporally.

\section{Fruit quality}

In addition to the genetic analyses being carried out within the EAGMAP, several related studies are underway. Consumer preference and sensory studies have been initiated with the Institute of Food Research, Reading, U.K., to quantify the range of variation currently available in marketed apple varieties. A trained panel is developing comprehensive descriptive sensory profiles for various varieties using peeled and unpeeled quarters of fruit. Apparently, very small quantities of experimental material can be used to give breeders a good definition of the sensory profile. Preliminary hedonic evaluation by a small sample of consumers also has been conducted, followed by internal preference mapping onto the sensory profiles. The aim of this work is to establish areas of consumer preference not served by current varieties and to map the sensory attributes onto genetic components. Samples of fruit from the reference mapping populations are being assessed to investigate segregation of sensory components. Detailed measurements of physical attributes, such as fruit stiffness, are also being carried out on existing varieties and samples from the mapping populations to provide validation of sensory profiles.

\section{Economic modeling}

The economic effects of manipulating the genetic constitution of the apple crop are being investigated by modeling the impact of pesticide use on the production process, human health, and the environment. The first stage of work carried out by the Scottish Agricultural College, Edinburgh, has involved development of econometric damage functions that measure the impact of pesticide externalities, such as pollution. Further work will involve assigning production costs to diverse geographical areas and, where possible, economic consequences arising from establishment of distinct varieties.

\section{DISCUSSION}

The work encompassed by the European Apple Genome Mapping Project covers a wide range of genetic and related studies. Considerable progress has been made in the establishment of reference populations and accumulation of genetic marker and phenotypic data. Linkages to major sources of disease resistance have been established. Methodologies are being developed for management and analysis of large amounts of interrelated data, with a focus on genetic linkage.

Using rigorous genetic information as a basis, a number of related studies have been initiated to provide apple breeders with a range of sophisticated tools for varietal selection and crop improvement.

\section{Literature Cited}

Alston, F.H. and I. Batlle. 1992. Genetic markers in apple breeding. Phytoparasitica 20:s89-s92.

Alston, F.H. and R. Watkins. 1975. Apple breeding at East Malling. Proc. Fifth Eucarpia Fruit Sec. Symp., TOP Fruit Breeding, Canterbury, U.K. 1973. p. $1-13$.

Arus, P., R. Messeguer, M. Viruel, K.R. Tobutt, E. Dirlewanger, F. Santi, R. Quarta, and E. Ritter. 1994. The European Prunus mapping projectProgress in the almond linkage map. Euphytica 77:97-100.

Brown, S.K. 1992. Genetics of apple. Plant Breeding Rev. 9:333-366. 
Chevreau, E. and F. Laurens. 1987. The pattern of inheritance in apple (Malus $\times$ domestica Borkh.): Further results from leaf isoenzyme analysis. Theor. Appl. Genet. 75:90-95.

Gardiner, S.E., J.M. Zhu, H.C.M. Whitehead, and C. Madie. 1994. The New Zealand apple genome mapping project. Euphytica 77:77-81.

Hemmat, M., N.F. Weeden, A.G. Manganaris, and D.M. Lawson. 1994. Molecular marker linkage map for apple. J. Hered. 85:4-11.

King, G.J. 1994. Progress in mapping agronomic genes in apple (The European Apple Genome Mapping Project). Euphytica 77:65-69.

King, G.J., F.H. Alston, I. Batlle, E. Chevreau, C. Gessler, J. Janse, P. Lindhout, A.G. Manganaris, S. Sansavini, H. Schmidt, and K.R. Tobutt. 1991. The European Apple Genome Mapping Project-Developing a strategy for mapping genes coding for agronomic characters in tree species. Euphytica 56:89-94.

Koller, B., L. Gianfranceschi, N. Seglias, J. McDermott, and C. Gessler. 1994. DNA markers linked to Malus floribunda $821 \mathrm{scab}$ resistance. Plant Mol. Biol. 26:597-602.

Korban, S.S. and S. Chen. 1992. Apple, p. 203-227. In: F.A. Hammerschlag and R.E. Litz (eds.). Biotechnology of perennial fruit crops. CAB International, Wallingford, Oxon

Lander, E.S. and D. Botstein. 1989. Mapping Mendelian factors underly- ing quantitative traits using RFLP linkage maps. Genetics 121:185199.

Maliepaard, C. and J.W. van Ooijen. 1994. QTL mapping in a full-sib family of an outcrossing species, p. 140-146. In: J.W. Van Ooijen and J. Jansen (eds.). Biometrics in plant breeding: Applications of molecular markers. Proc. Ninth Mtg. Eucarpia Section Biometrics in Plant Breeding. 6-8 July 1994, Wageningen, The Netherlands.

Manganaris, A.G. and F.H. Alston. 1987. Inheritance and linkage relationships of glutamate oxaloacetate transaminase isoenzymes in apple: 1 . The gene GOT-1, a marker for the S incompatibility locus. Theor. Appl. Genet. 74:154-161.

Manganaris, A.G., F.H. Alston, N.F. Weeden, H.S. Aldwinckle, H.L. Gustafson, and S.K. Brown. 1994. Isozyme locus PGM-1 is tightly linked to a gene (Vf) for scab resistance in apple. J. Amer. Soc. Hort. Sci. 119:1286-1288.

Markussen, T., J. Kruger, H. Schmidt, and F. Dunemann. 1995. Identification of PCR-based markers linked to the powdery mildew resistance $P l 1$ from M. robusta in cultivated apple. Plant Breeding 114: 530-534.

Stam, P. 1993. Construction of integrated genetic linkage maps by means of a new computer package: JoinMap. Plant J. 3:739-744.

Yang, H.Y. and J. Kruger. 1994. Identification of an RAPD marker linked to the Vf gene for scab resistance in apples. Plant Breeding 112:323-329.

\title{
Genetic Studies in Pea and Apple: The Yin and Yang of Mapping in Plants
}

\author{
Norman F. Weeden \\ Department of Horticultural Sciences, New York State Agricultural Experiment Station, Cornell University, \\ Geneva, NY 14456
}

From a genetic perspective, there may not be two horticultural crops as different as the garden pea (Pisum sativum $\mathrm{L}$ ) and domesticated apple (Malus $\times$ domestica Borkh.). Pea is a self-compatible, highly inbred crop that can be maintained from year to year by storing seed from true-breeding lines. Apple is generally self-incompatible, highly heterozygous, and varieties are maintained by clonal propagation. From these and other contrasting characteristics listed in Table 1, it is obvious why pea and not apple was used in many early genetic studies, and why it has been so successful as a model system. One may reasonably argue that the simple rules of inheritance never could have been revealed through studies on apple with its complications of selfincompatibility, chimerical mutants, large size, long generation time, and relatively few clearly expressed monogenic traits.

Fortunately, much of what has been learned through studies on pea or other model systems is directly applicable to genetically more intractable species. Thus, once Mendelian genetics had been demonstrated in pea, the same rules could easily be applied to apple, and apple breeders could at least gradually develop an understanding of the genetic basis for some of the more important characters in this crop. However, genetic analysis in pea has not been free of complications, particularly in dealing with the large size of the pea genome and the significant number of chromosomal rearrangements in the crosscompatible germplasm. In contrast, recently developed molecular markers such as randomly amplified polymorphic DNA (RAPDs) are especially well-suited for genetic analysis in apple. For these and other reasons, much of what is on the forefront of genetic research in pea is also being examined in apple. In a few instances, methods developed initially in apple have been useful when applied to pea genetic analysis.

Received for publication 29 Nov. 1995. Accepted for publication 28 Jan. 1996. This work was supported in part by U.S. Dept. of Agriculture National Research Initiative grant 91-37305-5969. I thank G.M. Timmerman-Vaughan and T.H.N. Ellis for sharing unpublished mapping results and S.K. Brown for a helpful review of this manuscript. The cost of publishing this paper was defrayed in part by the payment of page charges. Under postal regulations, this paper therefore must be hereby marked advertisement solely to indicate this fact.

\section{PEA GENETICS: PAST AND PRESENT}

There are both advantages and disadvantages to working with a widely studied model. One has access to powerful genetic tools, such as many well-characterized mutants, a linkage map in an advanced stage of assembly, well-defined germplasm, and genetic information on many complex characters. However, one also has to contend with an overwhelming volume of literature on the species and the need to develop an interaction with the numerous laboratories studying the organism to minimize duplication of effort and ensure integration of information. Furthermore, the rate at which progress is being made gives little time for a careful review of the literature so that previous data is often simply assumed to have been correctly interpreted.

By the early 1980 s, there were already more than 350 genes (mostly morphological mutants) described for pea (Blixt, 1975; Lamprecht, 1974), and more than 150 of these had been assembled into a linkage map consisting of seven linkage groups. Although much of the map was developed by combining data from two-point crosses, in only 13 cases was the distance between adjacent loci greater than $20 \mathrm{cM}$ (Blixt, 1972), suggesting a highly reliable map. Most of these linkage groups

Table 1. Contrasting genetic systems of pea and apple.

\begin{tabular}{lll}
\hline \hline & \multicolumn{1}{c}{ Phenotype } \\
\cline { 2 - 3 } Trait & \multicolumn{1}{c}{ Pea } & \multicolumn{1}{c}{ Apple } \\
\hline Habit & Herbaceous annual & Woody perennial \\
Generation time & Usuanths & 4-6 years \\
Height of plant & Inbred line & $2-10 \mathrm{~m}$ \\
Variety type & Clonal propagule \\
Compatibility & Self-compatible & Self-incompatible \\
Chromosome number $(n)$ & 7 & 17 \\
Postulated ploidy & Diploid & Diploidized tetraploid \\
Heterozygosity & Very low & High \\
Chimeral mutants & Few & Many \\
Genetic diversity & High within species & High within domesti- \\
& & cated germplasm \\
\hline
\end{tabular}


had been paired with chromosomes of the standard karyotype (Lamm and Miravalle, 1959). The taxonomy of the genus was relatively well established (Davis, 1970) and widely accepted, and considerable germplasm had been collected and was available in several genebanks around the world.

One aspect often overlooked by present-day geneticists working with molecular markers is that several complex traits, including flowering time (six major genes plus modifiers) and internode length (five major genes plus modifiers), had been dissected into their major components using classical crossing schemes, careful observation, and, in most cases, morphological markers to locate the genes on the linkage map (see review by Murfet and Reid, 1985). Thus, the analysis of quantitative traits was well established in pea (as well as certain other important crops), albeit proceeding at a slow rate, 20 years before DNA markers had popularized such analyses and greatly increased their efficiency.

With a conventional linkage map already available for pea, the obvious course for those wanting to map the new "molecular markers" [isozymes followed by restriction fragment length polymorphisms (RFLPs) and eventually polymerase chain reaction- (PCR) amplified fragments) was to locate the new markers on the existing map. Unfortunately, this task was not as easy as it first appeared, because although there were morphological marker lines available for mapping, each line usually possesses only five to 10 mutant genes, thus requiring several different crosses to obtain reasonable coverage of the known linkage map.

Mapping isozyme loci did little to alter this situation, considering only 46 polymorphic isozyme loci have been reported in pea (Weeden, 1988). However, with the virtually unlimited number of RFLP markers available, and because mapping 80 markers or more in a segregating population represented a significant commitment of time and resources, the "traditional" approach soon became untenable. Crosses between breeding lines rarely had sufficient genetic diversity to make a full-blown RFLP mapping study worthwhile, as only $10 \%$ to $20 \%$ of the probes would display RFLPs. Thus, a wider cross, similar to the Lycopersicon esculentum $\times$ L. pennellii (Correll) D'Arcy cross in tomato mapping (Bernatzky and Tanksley, 1986; Rick, 1969), had to be identified.

There are several subspecies of $P$. sativum. Crosses between two such subspecies revealed sufficient polymorphism for DNA probes. However, chromosomal rearrangements and other factors greatly reduced fertility in the $\mathrm{F}_{2}$ of many such crosses, and our program and that of Noel Ellis at the John Innes Institute, Norwich, U.K., struggled with several alternatives before identifying what seemed to be acceptable parents. We used a multiple-marker line called "Slow" that we had developed to possess morphological and isozyme markers and crossed it with a $P$. sativum ssp. humile Boiss. et Noe line that possessed several additional markers and, most importantly, gave a highly fertile $\mathrm{F}_{2}$. Ellis et al. (1992) concentrated on several crosses that gave many RFLPs and reasonably fertile $\mathrm{F}_{2} \mathrm{~s}$, but often did not possess many of the classical markers.

Even as the isozyme loci were being mapped, it became clear that there were serious deficiencies in the classical map. In two regions, isozyme markers extended the map to other regions not covered by the known morphological markers. In other cases, markers that should have shown linkage did not. RFLP markers further destabilized the classical map until we were forced to redefine several linkage groups (Weeden and Wolko, 1990). Ellis' program also encountered unexpected difficulties. Although the lack of classical markers segregating in their mapping populations prevented them from making detailed comparisons with the classical linkage groups, they occasionally found differences in linkage arrangements among the crosses they analyzed (Ellis et al., 1992). A few of these differences were expected as a result of known translocations, but most were puzzling. It appeared that we still had much to learn about the pea genome.

A concerted effort on the part of three laboratories (those of Noel Ellis; Gail Timmerman-Vaughan at Christchurch, New Zealand; and my own), along with help from many other pea geneticists, has produced a consensus pea linkage map containing morphological, isozyme, RFLP, and RAPD markers (Fig. 1). Linkage groups III and VI are similar to those on the classical map, but the others represent fractions, new combinations, or expansions of the linkage groups summarized in Blixt (1975).

Surprisingly, the new map has not coalesced into seven linkage groups despite the availability of $>1000$ markers and polymorphic genes. Not all these markers have been mapped in a single cross, but $>200$ markers have been mapped in each of at least six populations. Mapping 200 markers gives an average of 30 markers per chromosome and an average distance between markers of 6 to $8 \mathrm{cM}$, assuming a total linkage map length of 1200 to $1600 \mathrm{cM}$. One would expect the combined data on several populations to give excellent coverage of the genome. However, the problem regions appear to be reproducible in the various populations examined.

PCR techniques have increased the number of markers mapped in certain pea populations to $>500$; yet linkage groups I and IV remain in two or more fragments. RAPD markers have been particularly easy to map in recombinant inbred populations, and although they show some evidence of clustering, no significant portion of the known linkage map is devoid of RAPD markers. Even the few microsatellite markers (Dirlewanger et al., 1994) and amplified fragment length polymorphisms (AFLPs) (Timmerman-Vaughan, pers. commun.) that have been mapped in pea are located within the known linkage groups and have not helped to join them together.

In addition, myriad mapping experiments have been performed by others to locate specific genes or mutants. None of these mapping studies has provided compelling evidence for the synteny of two or more of the linkage groups shown in Fig. 1. For example, researchers at Novosibirsk have made a special effort to pair the short linkage group IA with another linkage group. They have extended that linkage group another $30 \mathrm{cM}$ beyond lf, and yet the distal markers, $b l b$ and His7, still fail to display linkage with markers on linkage group IB or any of the markers tested on other groups (Kosterin, 1993; Kosterin and Rozov, 1993). We are forced to conclude that there must be regions on the pea genome that have both high recombination frequency and low marker density (irrespective of marker type).

\section{MARKER-ASSISTED SELECTION IN PEA}

Despite the somewhat frustrating state of affairs in the development of a highly saturated map for pea, the use of markers in pea breeding and genetics is progressing rapidly. Three important virus resistance genes ( $m o, s b m-1$, and $E n$ ) have been precisely mapped and tagged with molecular markers. The closest marker to $s b m-1$ remains an RFLP about $8 \mathrm{cM}$ away (Timmerman et al., 1993), but $E n$ and $m o$ have specific primer sets that permit convenient and economical screening of many individuals (Yu et al., 1995, 1996). Specific primers for er-1, a gene conferring resistance to powdery mildew (Erysiphe pisi Syd.), also has been developed (Timmerman et al., 1994). Pea genes appropriate for marker-assisted selection have been tagged (Table 2).

The precise mapping of some of these genes has helped resolve some contradictory reports in the literature regarding linkages. For instance, the gene $e r-1$ was first reported to be linked to $a$ on linkage group I (Harland, 1948). Subsequent investigations by Marx (1971) demonstrated clear linkage between er 1 and the morphological marker "Gritty" (Gty), which was thought to be on linkage group III; however, tests with other markers on linkage group III failed to confirm association of er- 1 with that linkage group (Marx, 1986). Weeden and Wolko (1990) showed that Gty was on linkage group VI rather than III, and suggested that er- 1 might also be on linkage group VI. Finally, Gupta et al. (1992) reported a gene conferring resistance to powdery mildew was on linkage group V. Unfortunately, the latter group was working with a source of resistance that differed from those of the previous experiments, and this alternate source may have possessed a second resistance gene, $e r-2$, or another gene not previously described. Although this set of conflicting reports represents one of the worst examples of confusion regarding the locus position in pea, it is certainly not the only example. The development of a reliable DNA marker for $e r-1$ by Timmerman et al. (1994) firmly established the position of $e r-1$ on linkage group VI and provided a convenient method for testing for this gene in many other crosses segregating for powdery mildew resistance. 

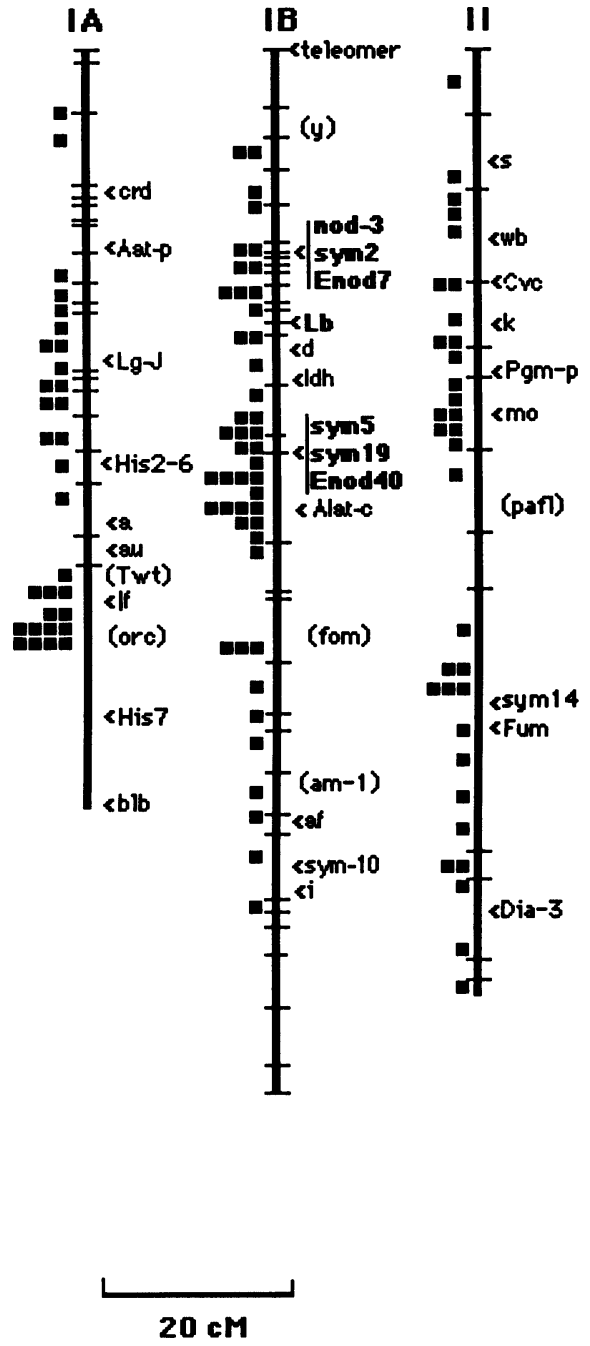
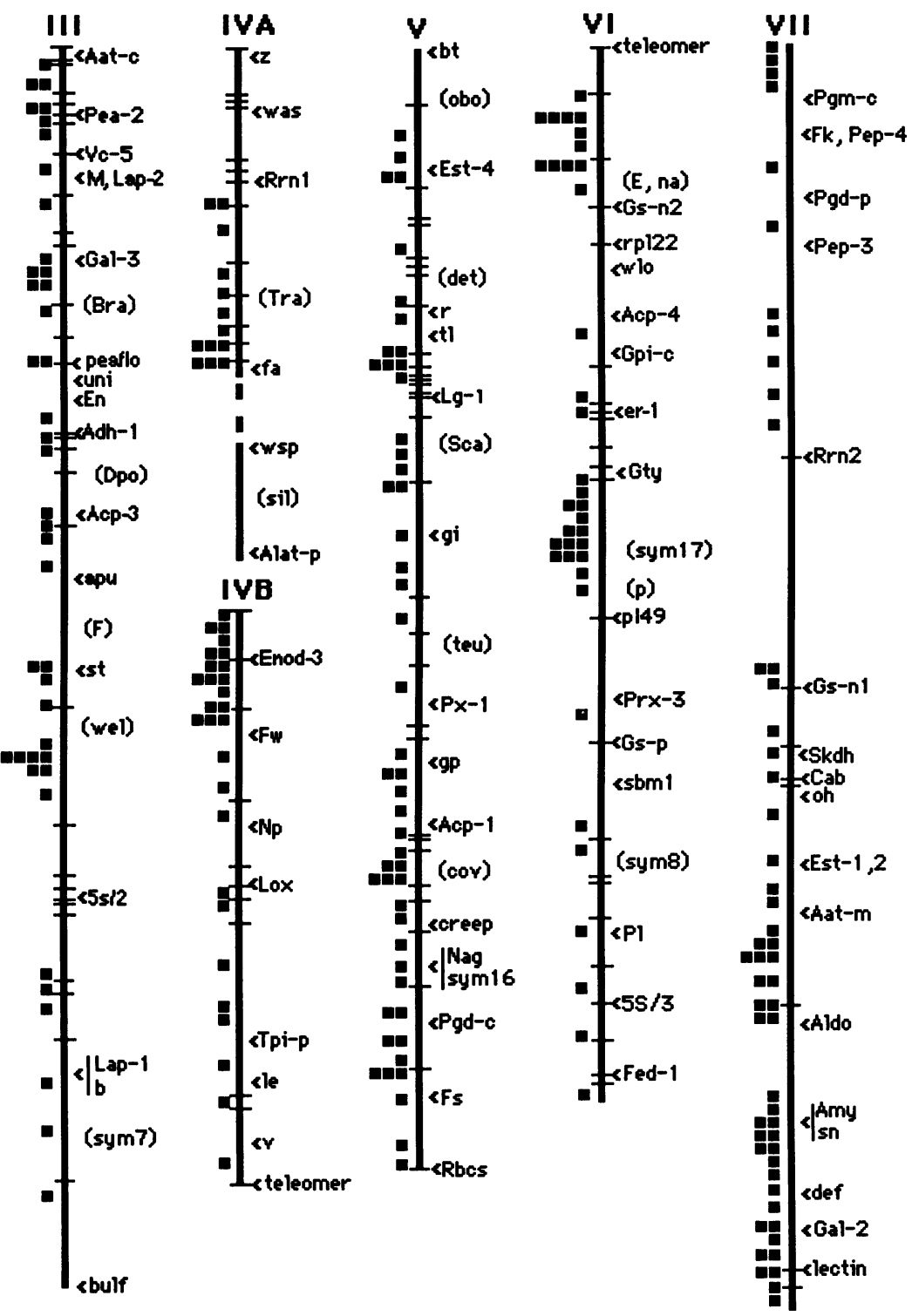

Fig. 1. Current consensus linkage map for Pisum sativum. The positions of common morphological mutants and some known genes mapped by RFLP analysis are given to the right of the heavy vertical bar representing the linkage group. Positions of other mapped RFLPs or stable sequence characterized amplified regions (SCARs) are shown as hatch marks on the bar. Positions of RAPDs are shown as boxes to the left of the bar. Approximate positions of certain other morphological mutants are given in parentheses. About one-third of the morphological markers described in pea are not shown on the map because their precise positions relative to the given markers are not known. A similar fraction of RFLPs and RAPDs are not shown because in the crosses in which these markers were assembled into linkage groups, the linkage groups on which they were placed could not be paired with one of the standard linkage groups.

\section{ANALYSIS OF COMPLEX CHARACTERS}

As mentioned, some complex traits, such as flowering time and plant height, were carefully analyzed and at least partly resolved into their genetic components before the appearance of molecular markers. These studies required the observation of minor qualitative differences

Table 2. Genes conferring disease resistance in pea for which marker-assisted selection using molecular markers is currently feasible.

\begin{tabular}{llll}
\hline \hline Gene & \multicolumn{1}{c}{ Disease } & Marker & \multicolumn{1}{c}{ Reference } \\
\hline cyv-1 & Clover yellow vein virus & B302 & Yu et al., 1996 \\
$c y v-2$ & Clover yellow vein virus & Gs-p & Timmerman et al., 1993 \\
En & Pea enation mosaic virus & P256 & Yu et al., 1995 \\
er-1 & Powdery mildew & PD10 & Timmerman et al., 1994 \\
$F w$ & Fusarium wilt (race 1) & p254 & Dirlewanger et al., 1994 \\
$m o$ & Bean yellow mosaic virus & B302 & Yu et al., 1996 \\
Rap-2 & Ascochyta blight & p105 & Dirlewanger et al., 1994 \\
sbm-1 & Pea seedborne mosaic virus & Gs-p & Timmerman et al., 1993 \\
sbm-3 & Lentil strain PSbMV & B302 & Yu et al., 1996 \\
& Common root rot tolerance & OPA5 & Cargnoni et al., 1994 \\
\hline
\end{tabular}

segregating in an $\mathrm{F}_{2}$ population and correlation of the segregation pattern with that of an easily scored morphological marker. Thus, the approach differed considerably from that used in mapping quantitative trait loci (QTL) today (Tanksley, 1993). However, the end result was a set of well-defined genes that could account for most of the variability in plant height or flowering time observed in any population segregating for the character. For nearly every complex trait examined, the individual contributing loci assorted independently and showed a variety of epistatic or complex interactions (Marx, 1985; Murfet and Reid, 1985).

More recently, several molecular-marker-based QTL studies have been completed for other traits in pea. QTLs for seed size and color retention have been identified by Timmerman-Vaughan et al. (1995). Several of the QTLs mapped in the region of genes that had been described previously as affecting the respective character. Indeed, the QTL may simply represent an alternate allele at the previously defined locus, and perhaps many of the loci already described in pea have "cryptic alleles" with effects too small to be scored as qualitative traits but recognizable using more powerful approaches.

Resistance to Ascochyta pisi Lib. race C was initially believed to be 
controlled by several genes (Lyall and Wallen, 1958; Wark, 1950); however, Cousins (1974) suggested that resistance was primarily determined by a single major gene with several modifiers. Darby et al. (1985) appeared to confirm the existence of this major gene, designating it Rap-2 and mapping it near $i$ on linkage group IB. Dirlewanger et al. (1994) revisited the problem using a molecular-marker-based QTL approach. These researchers also obtained evidence for a major gene, but in this case the primary QTL was placed on linkage group IV. A QTL with minor effect was located near $i$ and another near er -1 . The contrasting findings of the two studies may have resulted from the different sources of Ascochyta resistance, various Ascochyta strains used in the experiments, or a further example of inconsistency of mapping results with different genetic backgrounds.

\section{PEA AS A MODEL SYSTEM TO STUDY THE GENETICS OF NODULATION AND NITROGEN FIXATION}

In flowering plants, the capability to fix nitrogen is primarily limited to legumes, many species of which can form nodules on their roots. The root nodule is a product of a symbiotic relationship between a soil bacterium (Rhizobium leguminosarum Frank in the case of pea) and the host plant. Bacterial and plant genes are required for this action, but although the bacterial genes have been cloned and sequenced, those in the host plant have been difficult to identify or characterize.

Despite its large genome, pea has been particularly amenable to genetic studies on nodule formation and metabolism and certainly ranks among the best model systems for exploring these complex traits. To identify host genes involved in nodulation, several laboratories have used mutagens to generate pea mutants that do not nodulate or produce abnormal nodules (Duc and Messager, 1989; Engvild, 1987; Kneen and LaRue, 1988; Postma et al., 1988, Tsyganov et al., 1995). In addition, several nodulins (genes abundantly or uniquely expressed in the nodule) have been identified in pea (Franssen et al., 1992).

More than 40 mutants in some way defective in nodulation capacity have now been isolated, and although allelism tests are still being performed, at least 30 genes have been defined, including those coding the nodulins leghemoglobin, ENOD2, ENOD5, ENOD7, ENOD13, and ENOD40. Except for linkage group IVB, each linkage group has at least one locus affecting the nodule function region (Kneen et al., 1994; Weeden et al., 1991). However, linkage group IB appears to have more genes than expected, possessing three nodulin loci $(L b$, Enod7, and Enod40) and four mutants (sym2, sym5, sym19, and nod3 ) within $30 \mathrm{cM}$ of each other plus a fourth mutant (sym10) near $i$. This region is particularly intriguing because genes involved in the same metabolic pathway or otherwise functionally related are rarely closely linked in higher eukaryotes. In those cases where linkage between functionally related genes does occur (seed protein genes, ribosomal repeats, disease resistance genes), the genes usually form very tight clusters and are believed to be related by gene duplication. The noduleassociated genes on linkage group IB do not appear to be related by gene duplication and thus form a unique type of loose cluster not previously described in plants.

\section{APPLE GENETICS}

Apple represents quite a change of pace from the pea model. Instead of three to four generations per year, apple has one generation every 4 to 6 years. The researcher also has the disadvantage of working with a self-incompatible diploidized tetraploid $(2 n=34)$. However, the apple has one important character, a high level of heterozygosity, that makes genetic studies not only feasible but also surprisingly easy to perform. In contrast to pea and other inbred, homozygous crops, an apple variety may itself be considered an $\mathrm{F}_{1}$, and the progeny produced by a cross with any other variety will segregate for the heterozygous loci in the original variety. In fact, the progeny will segregate at loci heterozygous in each of the parents, and the breeder/geneticist can take great advantage of this "double pseudo-testcross" format (Hemmat et al., 1994; Weeden et al., 1994).

Apple is not unique for this character. Many outcrossing animals and plants also display high heterozygosity within individuals. Coni- fer geneticists have combined the technique with the availability of haploid megagametophytic tissue to obtain segregation ratios in gametes from a single plant (Guries et al., 1978; O'Malley et al., 1979). The double pseudo-testcross format is also prevalent in fruit crops such as pear (Pyrus communis Thunb.) and grape (Vitis spp.), in other woody genera such as Eucalyptus (Grattapaglia and Sederoff, 1994), and in outcrossing herbaceous crops such as asparagus (Asparagus officianalis L.) (Jiang and Sink, 1994). As virtually every cross in these crops will produce a segregating progeny, populations in the field or seed stored from previous years are valuable resources for genetic studies.

Certain apple varieties ('Golden Delicious', 'Red Delicious', 'Fuji', etc.) have proven to be excellent parents and are part of many pedigrees. Genetic maps for these varieties would be particularly valuable because genetic linkages or markers identified in them could be immediately applied to numerous other varieties or populations. This situation is very different from that in pea, where linkage maps must be constructed de novo for a population due to the lack of marker information for the parental lines. Those of us particularly interested in completing at least one pea linkage map have switched to the apple breeder's approach and identified specific lines to be worked on jointly by several laboratories (Weeden et al., 1993).

A critical aspect of the double pseudo-testcross format is that, for those loci heterozygous in only one parent, the progeny should segregate $1: 1$, just as in a testcross, and the phenotype will reflect the genotype. In this situation, dominant markers such as RAPDs have the same information content as codominant isozymes or RFLPs. Thus, linkage maps consisting primarily of RAPD markers can be constructed very efficiently and quickly, and bulked segregant analysis (Michelmore et al., 1991) is easily performed.

With the aid of the pseudo-testcross approach, molecular marker studies in apple have proceeded much faster than anyone predicted. Maps are available for several varieties (Conner, 1996; Hemmat et al, 1994; King, 1996), and the map developed for 'White Angel' has been condensed to the predicted number of linkage groups (17) plus two very short groups. In this respect, the genetics of apple appears to be slightly more advanced than that of pea, although the number of mapped loci and markers is much greater in pea.

Identification of DNA tags for important genes is proceeding rapidly in Europe and the United States. DNA markers have been established for six genes in apple (Table 3), and it appears that, given the appropriate germplasm, finding a marker in apple is no more difficult that finding one in pea. Similarly, the genetic dissection of complex traits appears to be achievable in apple (Conner, 1996; Lawson et al., 1995). Unfortunately, one set of characters of primary importance in apple involves fruit quality. For a thorough QTL analysis of such characters, time and space will always be obstacles, although the concerted approach being taken by the European Apple Group (King, 1996) should permit excellent data to be obtained. Once genes are tagged, they should be much easier to clone in apple than in pea due to the significantly smaller genome of the former crop.

\section{CONCLUDING COMMENTS}

Although the pea appears to be a much easier crop on which to perform genetic analyses and was the object of formal genetic studies long before apple, progress in apple is now nearly as rapid as that in pea. In part, this near equivalency is testimony to the power of the new technologies available to modern geneticists. DNA markers have, in a

Table 3. Genes in apple for which marker-assisted selection using molecular markers is currently feasible.

\begin{tabular}{llll}
\hline \hline Gene & \multicolumn{1}{c}{ Function } & Marker & \multicolumn{1}{c}{ Reference } \\
\hline$V f$ & Resistance to apple scab & $\begin{array}{l}\text { Pgm-1 } \\
\text { OD20 }\end{array}$ & $\begin{array}{l}\text { Manganaris et al., 1994 } \\
\text { Yang and Krüger, 1994 }\end{array}$ \\
$P l$ & $\begin{array}{l}\text { Resistance to powdery } \\
\text { mildew }\end{array}$ & Lap-2 & Manganaris and Alston, 1992 \\
& Self-incompatibility & Aat-1 & Manganaris and Alston, 1987 \\
Co & Columnar habit & OA11 & Hemmat et al., 1995 \\
$T b$ & Terminal bearing & P27 & Lawson et al., 1995 \\
$R b$ & Reproductive budbreak & P163 & Lawson et al., 1995 \\
\hline
\end{tabular}


sense, leveled the playing field, obliterating many of the advantages possessed by early model systems. Generating a linkage map or identifying a DNA marker tightly linked to a particular gene is now routine. Morphological markers linked to genes of interests have become obsolete despite years of development. The identification of genes through careful observation of segregating phenotypes has been at least partially replaced by QTL analysis and production of cDNA libraries, both of which can be much more efficient approaches. Hence, not surprisingly, many crops previously avoided by geneticists can quickly be transformed into organisms that are genetically wellcharacterized.

Model systems, at least in molecular genetics, now require an organism with a small genome, short generation time, and considerable genetic diversity. With a genome five- to 10-fold larger than some other important legumes, pea will be used as a model system only when it offers something in addition to historical precedence, such as the many nodulation mutants that appear to be difficult to generate in other legume species. In addition, the popularity of pea among plant physiologists and biochemists assures that the species will continue to play an important role in basic research. Most importantly, pea remains an important crop. Marker-assisted selection can now be performed for many critical traits, and many more genes will soon be tagged and characterized. Although apple and many other crops may no longer have to play second fiddle to pea in terms of access to genetic tools, pea is not about to be left behind in the use of modern technologies to transfer genes from one genetic background to another. As transformation of pea is also being accomplished in several laboratories, the whole diversity of life is now available to the pea breeder.

\section{Literature Cited}

Bernatzky, R. and S.D. Tanksley. 1986. Toward a saturated linkage map in tomato based on isozymes and random cDNA sequences. Genetics 112:887898.

Blixt, S. 1972. Mutation genetics in Pisum. Agr. Hort. Genet. 30:1-293.

Blixt, S. 1975. The pea, p. 181-221. In: R.S. King (ed.). Handbook of genetics. vol. 2. Plenum Press, New York.

Cargnoni, T.L., N.F. Weeden, and E.T. Gritton. 1994. A DNA marker correlated with tolerance to Aphanomyces root rot is tightly linked to Er-1.Pisum Genet. 26:11-12.

Conner, P.J. 1996. Examination of apple (Malus $\times$ domestica) fruit quality and tree and fruit morphology using molecular markers. PhD Diss., Cornell Univ., Ithaca, N.Y.

Cousins, R. 1974. Le pois. In: Etude génétique des caractéres, classification, caracteristiques variétales portant sur les variétés inscrites au catalogue officiel français. Inst. Natl. Recherche Agronomique, Paris.

Darby, P., B.G. Lewis, and P. Matthews. 1985. Inheritance and expression of resistance to Ascochyta pisi, p. 231-236. In: P.D. Hebblethwaite, M.C. Heath, and T.C.K. Dawkins (eds.). The pea crop: A basis for improvement. Butterworths, London.

Davis, P.H. 1970. Flora of Turkey. vol. 3. Edinburgh University Press, Edinburgh, Scotland. p. 370-373.

Dirlewanger, E., P.G. Isaac, S. Ranade, M. Belajouza, R. Cousin, and D. de Vienne. 1994. Restriction fragment length polymorphism analysis of loci associated with disease resistance genes and developmental traits in Pisum sativum L. Theor. Appl. Genet. 88:17-27.

Duc, G. and A. Messager. 1989. Mutagenesis of pea (Pisum sativum L.) and the isolation of mutants for nodulation and nitrogen fixation. Plant Sci. 60:207213.

Ellis, T.H.N., L. Turner, R.P. Hellens, D. Lee, C.L. Harker, C. Enard, C. Domoney, and D.R. Davies. 1992. Linkage maps in pea. Genetics 130:649663.

Engvild, K.G. 1987. Nodulation and nitrogen fixation mutants of pea, Pisum sativum. Theor. Appl. Genet. 74:711-713.

Franssen, H.J., J.P. Nap, and T. Bisseling. 1992. Nodulins in root nodule development, p. 598-624. In: G. Stacey, R.H. Burris, and H.J. Evans (eds.). Biological nitrogen fixation. Chapman and Hall, London.

Grattapaglia, D. and R. Sederoff. 1994. Genetic linkage maps of Eucalyptus grandis and Eucalyptus urophylla using a pseudo-testcross mapping strategy and RAPD markers. Genetics 137:1121-1137.

Gupta, M.D., B. Sharma, and S.K. Mishra. 1992. Genetics of powdery mildew resistance in pea (Pisum sativum), p. 59. In: Second Intl. Food Legume Res. Conf. Prog. \& Abstr., 6-11 July 1986, Spokane, Wash.

Guries, R.P., S.T. Friedman, and F.T. Ledig. 1978. A megagametophytic analysis of genetic linkage in pitch pine (Pinus rigida Mill.). Heredity 40:309-314.
Harland, S.C. 1948. Inheritance of immunity to mildew in Peruvian forms of Pisum sativum. Heredity 2:263-269.

Hemmat, M., N.F. Weeden, A.G. Manganaris, and D.M. Lawson. 1994. Molecular marker linkage map for apple. J. Hered. 85:4-11.

Hemmat, M., N.F. Weeden, P. Conner, and S.K. Brown. 1995. A DNA marker for columnar growth habit in apple contains a simple sequence repeat, p. 86 . In: Plant Genome III, Final Prog. \& Abstr., 15-19 Jan. 1995, San Diego.

Jiang, C. and K.C. Sink. 1994. RAPD mapping of the asparagus (Asparagus officianalis L.) genome. HortScience 29:497. (Abstr.)

King, G.J. 1996. Progress of apple genetic mapping in Europe. HortScience 31:1107-1110

Kneen, B.E. and T.A. LaRue. 1988. Induced symbiosis mutants of pea (Pisum sativum) and sweet clover (Melilotus alba). Plant Sci. 58:177-182.

Kneen, B., N.F. Weeden, and T.A. LaRue. 1994. Non-nodulating mutants of Pisum sativum (L.) cv. 'Sparkle'. J. Hered. 85:129-133.

Kosterin, O.E. 1993. Genes $a$ and $d$ may not be in the same linkage group. Pisum Genet. 25:23-26.

Kosterin, O.E. and S.M. Rozov. 1993. Mapping of the new mutation $b l b$ and the problem of integrity of linkage group 1. Pisum Genet. 25:27-31.

Lamm, R. and J.R. Miravalle. 1959. A translocation tester set in Pisum. Hereditas 45:417-440.

Lamprecht, H. 1974. Monographie der Gattung Pisum. Steiermarkische Landesdruckerei, Graz.

Lawson, D.M., M. Hemmat, and N.F. Weeden. 1995. The use of molecular markers to analyze the inheritance of morphological and developmental traits in apple. J. Amer. Soc. Hort. Sci. 120:532-537.

Lyall, L. and V.R. Wallen. 1958. The inheritance of resistance to Ascochyta pisi Lib. in peas. Can. J. Plant Sci. 38:215-218.

Manganaris, A.G. and F.H. Alston. 1987. Inheritance and linkage relationships of glutamate oxaloacetate transaminase isoenzymes in apple. 1. The gene GOT-1, A marker for the $S$ incompatibility locus. Theor. Appl. Genet. 74:154-161.

Manganaris, A.G. and F.H. Alston. 1992. Genetics of leucine aminopeptidase in apple. Theor. Appl. Genet. 83:345-352.

Manganaris, A.G., F.H. Alston, N.F. Weeden, H.S. Aldwinckle, H.L. Gustafson, and S.K. Brown. 1994. Isozyme locus Pgm-1 is tightly linked to a gene ( Vf) for scab resistance in apple. J. Amer. Soc. Hort. Sci. 119:1286-1288.

Marx, G.A. 1971. New linkage relations for chromosome III of Pisum. Pisum Nwsl. 3:18-19.

Marx, G.A. 1985. The pea genome: a source of immense variation, p. 45-54. In: P.D. Hebblethwaite, M.C. Heath, and T.C.K. Dawkins (eds.). The pea crop: A basis for improvement. Butterworths, London.

Marx, G.A. 1986. Location of er proving elusive. Pisum Nwsl. 18:39-41.

Michelmore, R.W., I. Paran, and R.V. Kesseli. 1991. Identification of markers linked to disease resistance genes by bulked segregant analysis: A rapid method to detect markers in specific genomic regions by using bulked segregant populations. Proc. Natl. Acad. Sci. USA 88:9828-9832.

Murfet, I.C. and J.B. Reid. 1985. The control of flowering and internode length in Pisum, p. 67-80. In: P.D. Hebblethwaite, M.C. Heath, and T.C.K. Dawkins (eds.). The pea crop: A basis for improvement. Butterworths, London.

O'Malley, D.M., F.M. Allendorf, and G.M. Blake. 1979. Inheritance of isozyme variation and heterozygosity in Pinus ponderosa. Biochem. Genet. 17:233-250.

Postma, J.G., E. Jacobsen, and W.J. Feenstra. 1988. Three pea mutants with an altered nodulation studied by genetic analysis and grafting. J. Plant Physiol. 132:424-430.

Rick, C.M. 1969. Controlled introgression of chromosomes of Solanumpennellii into Lycopersicon esculentum: Segregation and recombination. Genetics 62:753-768.

Tanksley, S.D. 1993. Mapping polygenes. Annu. Rev. Genet. 27:205-233.

Timmerman, G.M., T.J. Frew, A.L. Miller, N.F. Weeden, and W.A. Jermyn. 1993. Linkage mapping of $s b m-1$, A gene conferring resistance to pea seedborne mosaic virus, using molecular markers in Pisum sativum. Theor. Appl. Genet. 85:609-615.

Timmerman, G.M., T.J. Frew, N.F. Weeden, A.L. Miller, and W.A. Jermyn. 1994. Linkage analysis of er-1, A recessive Pisum sativum gene for resistance to powdery mildew fungus (Erysiphe pisi). Theor. Appl. Genet. 88:1050-1055.

Timmerman-Vaughan, G., J. McCallum, T. Frew, and N. Weeden. 1995. QTL mapping seed traits in pea, p. 81. In: Plant Genome III, Final Prog. \& Abstr., 15-19 Jan. 1995, San Diego.

Tsyganov, V.E., A.Y. Borsiov, S.M. Rozov, and I.A. Tikhonovich. 1995. New symbiotic mutants of pea obtained after mutagenesis of line SGE. Pisum Genet. 26:36-37.

Wark, D.C. 1950. The inheritance of resistance to Ascochyta pisi Lib. in Pisum sativum L. Austral. J. Agr. Res. 1:382-390.

Weeden, N.F. 1988. Polymorphic isozyme loci identified in Pisum. Pisum Nwsl. 20:46-48. 
Weeden, N.F., B.E. Kneen, and T.A. LaRue. 1991. Genetic analysis of sym genes and other nodule-related genes in Pisum sativum, p. 323-330. In: P. Gresshoff et al. (eds.). Nitrogen fixation: Achievements and objectives. Chapman and Hall, New York.

Weeden, N.F., W.K. Swiecicki, G.M. Timmerman, and M. Ambrose. 1993. Guidelines for future mapping studies in Pisum. Pisum Genet. 25:13-14.

Weeden, N.F., M. Hemmat, D.M. Lawson, M. Lodhi, R.L. Bell, A.G. Manganaris, B.I. Reisch, S.K. Brown, and G.-N. Ye. 1994. Development and application of molecular marker linkage maps in woody fruit crops. Euphytica 77:71-75.
Weeden, N.F. and B. Wolko. 1990. Linkage map for the garden pea (Pisum sativum) based on molecular markers, p. 6.106-6.112. In: S.J. O'Brien (ed.). Genetic maps. 5th ed. Cold Spring Harbor Laboratory Press, Cold Spring Harbor, N.Y.

Yang, H. and J. Krüger. 1994. Identification of an RAPD marker linked to the $V f$ gene for scab resistance in apples. Plant Breeding 112:323-329.

Yu, J., W.K. Gu, R. Provvidenti, and N.F. Weeden. 1995. Identifying and mapping two DNA markers linked to the gene conferring resistance to pea enation mosaic virus. J. Amer. Soc. Hort. Sci. 120:730-733.

Yu, J. and N.F. Weeden. 1996. A DNA marker for the $M_{O}$ locus. Pisum Genet. 28:(In press)

\title{
Molecular Markers and Mapping in Bulb Onion, A Forgotten Monocot
}

\author{
Michael J. Havey ${ }^{1}$ and Joseph J. King ${ }^{2}$ \\ U.S. Department of Agriculture, Agricultural Research Service, Department of Horticulture, 1575 Linden Drive, \\ University of Wisconsin, Madison, WI 53706
}

\author{
James M. Bradeen ${ }^{3}$ and Ockyung Bark ${ }^{3}$ \\ Department of Horticulture, 1575 Linden Drive, University of Wisconsin, Madison, WI 53706
}

\begin{abstract}
Onion (Allium cepa L.) has been cultivated as a food, medicine, or religious crop since prehistoric times (McCollum, 1976). It originated in Central Asia and spread first to India and the Middle East, through Europe and Africa, to the Americas, and then to eastern Asia (Bark and Havey, 1995; Havey, 1993b; McCollum, 1976). Except for a few isolated indigenous groups and a religious sect in India, onion is consumed regularly by all of the world's cultures. Among freshmarket vegetables in the United States, the annual value of onion follows only tomato and lettuce (U.S. Dept. of Agriculture, 1992). At the current increase of $5 \%$ per year, the annual worth of onion will exceed U.S. \$1 billion by the year 2000 (Love, 1994).

The onion characteristics of diploidy $(2 n=2 x=16)$, historical maintenance by open pollination (Magruder et al., 1941), severe inbreeding depression (Jones and Davis, 1944), and significant heterosis (Jones and Davis, 1944; Joshi and Tandon, 1976) resemble maize (Zea mays L.), and our mapping experiences have allowed us to compare the structures of these two genomes. Today, hybrid-onion cultivars dominate many of the world's primary production areas. Genetic improvement of onion is a slow process because 2 years (seedto-bulb and bulb-to-seed) are required to complete one generation. Because of the slow generation time and the high cost of vernalizing bulbs before flowering, the development of elite onion inbreds, hybrids, and populations may benefit from marker-facilitated selection. Here, we describe research to identify and map restriction fragment length polymorphisms (RFLPs) and randomly amplified polymorphic DNA (RAPDs) to develop a low-density genetic map of onion. We intend to use this map to study chromosome regions controlling phenotypically correlated production, flavor, and health-enhancing attributes. We also explain the use of a polymorphism in the chloroplast genome that reduces the investment required to develop hybrids from open-pollinated onion populations.
\end{abstract}

Received for publication 29 Nov. 1995. Accepted for publication 28 Jan. 1996. The financial support of USDA-NRICGP 92-37300-7546, Rio Colorado, Sakata, Shippo, SunSeeds, and S\&G/Sandoz is gratefully acknowledged. Names are necessary to report factually on available data; however, the USDA neither guarantees nor warrants the standard of the product, and the use of the name by the USDA implies no approval of the product to the exclusion of others that may also be suitable. The cost of publishing this paper was defrayed in part by the payment of page charges. Under postal regulations, this paper therefore must be hereby marked advertisement solely to indicate this fact.

${ }^{1}$ USDA Research Geneticist and Associate Professor of Horticulture. To whom reprint requests should be addressed.

${ }^{2}$ USDA Postdoctoral Research Geneticist.

${ }^{3}$ Former Graduate Research Assistant.

\section{VARIABILITY FOR RFLPS AMONG ONION POPULATIONS}

Detecting RFLPs in onion requires careful attention at every step because it has one of the largest genomes among cultivated plants [17.9 pg (Labani and Elkington, 1987) = 15,290 megabp (Arumuganathan and Earle, 1991) per 1C (haploid DNA content) nucleus; 6.2, 16.3, and 107 times more than maize, tomato (Lycopersicon esculentum Mill.), and Arabidopsis, respectively]. We identified 60 random nuclear RFLPs among 17 open-pollinated (OP) populations of bulb onion (Bark and Havey, 1995) and estimated similarities and relationships. The average number of polymorphic fragments per polymorphic probe-enzyme combination was 1.9 , reflecting that numerous monomorphic fragments were usually present. Only $4 \%$ of cDNA probes detected RFLPs for three or four restriction enzymes, indicating that a majority of polymorphisms are likely due to differences at or near restriction-enzyme sites (Bark and Havey, 1995). These results differ from maize, in which there were on average four polymorphic fragments per polymorphic probe-enzyme combination (Gerdes and Tracy, 1994; Melchinger et al., 1991) and most RFLPs were due to structural changes between restriction-enzyme sites (Helentjaris et al., 1985). Relationships among OP populations were estimated by cladistic, phenetic, and multivariate analyses (Bark and Havey, 1995). We identified two divergent populations useful for mapping the maximum number of markers: 'Alisa Craig' (AC) is grown in the United Kingdom and 'Brigham Yellow Globe' (BYG) is grown in the eastern United States (Magruder et al., 1941).

\section{DEVELOPMENT OF A LOW-DENSITY GENETIC MAP FOR ONION}

There is a paucity of genetic markers in onion; only 20 morphological and disease-resistance loci have been described, of which four are lethal chlorophyll deficiencies expressed only in seedlings (Rabinowitch, 1988). Isozyme markers have been primarily identified between onion and other Allium species (Peffley and Castillo, 1987; Peffley et al., 1985) or in seed-storage proteins (Hadacova et al., 1981). Based on an average of 19 chiasmata per meiosis (Albini and Jones, 1988 ), we estimated the genetic map of onion to be $\approx 10 \mathrm{M}$ and expect that a minimum of 100 markers are required to achieve an average distance of $10 \mathrm{cM}$ between markers. For our low-density map to be of practical use, we identified markers only within cultivated germplasm.

We chose a segregating family from the cross of inbreds selected out of AC and BYG. Because of severe inbreeding depression, onion inbreds are rarely self-pollinated for more than two generations 
(Havey, 1993b). AC43 and BYG15-23 were developed by selfpollinating single bulbs from the OP populations for one and two generations, respectively. A single $\mathrm{F}_{1}$ plant from the cross BYG15-23 $x$ AC43 was self-pollinated to generate the $F_{2}$ family (gift of J.F. Watson, SunSeeds, Brooks, Ore.). Sixty $\mathrm{F}_{3}$ families were generated, without conscious selection, from self-pollinating individual $\mathrm{F}_{2}$ bulbs. Bulked DNAs for all RFLP and RAPD analyses were isolated from leaf tissue of at least 20 seedlings of each $\mathrm{F}_{3}$ family. All $\mathrm{F}_{2}$ plants were testcrossed to a sterile line and scored for 1$)$ the nuclear allele $(M S)$ that restores fertility in cytoplasmic-male-sterile lines (Jones and Clarke, 1943) and 2) complementary genes conditioning unacceptable pink- to red-skinned bulbs when some North American and European inbreds are crossed (Jones and Peterson, 1952).

\section{RFLPS}

RFLPs for mapping were detected with cDNA (Bark and Havey, 1995 ) and $P s t \mathrm{I}$-genomic clones (kindly provided by Pioneer Hybrid, Johnston, Iowa). We have established that $37 \%$ of cDNA probes detected RFLPs between AC43 and BYG15-23 digested with two to four restriction enzymes (Bark and Havey, 1995). To date, we have identified 200 RFLPs between the parents of our mapping family. However, due to residual heterozygosity in the parental inbreds, $\approx 38 \%$ of our polymorphic probe-enzyme combinations do not segregate.

\section{RAPDS}

Of 580 primers examined (kits A through E and AA through AX; Operon, Alemada, Calif.), 527 failed to reliably amplify a polymorphism between BYG15-23 and AC43 (all amplifications repeated twice). Of the 527, 22 failed to amplify any clearly defined RAPD bands, 30 amplified a polymorphism that was ambiguous or that could not be repeated, and 475 detected no polymorphism. Of the 53 primers amplifying polymorphisms between BYG15-23 and AC43, only 15 segregated and 12 of those fit the expected $3: 1$ ratio $(P>0.05)$. We attribute this loss of segregation to heterozygosity in the parental inbreds or ambiguities in the presence of polymorphic bands among $\mathrm{F}_{3}$ families, which reduced the number of usable polymorphic RAPD primers to 15. Twelve fit the expected 3:1 ratio $(P>0.05)$ (Bradeen and Havey, 1995). Although we were disappointed in the number of normally segregating RAPDs, we are confident that our replicated reactions provided an objective assessment of RAPDs in onion. To more efficiently identify RAPDs in a highly heterozygous crop such as onion, a better approach would be to evaluate a random sample of $\approx 10 \mathrm{~F}_{3}$-family DNAs instead of the parental inbreds to reveal segregating RAPDs that appear monomorphic between heterozygous parents.

\section{SEGREGATION ANALYSIS}

We have completed segregation analysis of 77 polymorphisms, 66 of which formed 12 linkage groups and 11 were unlinked. As expected, we have not resolved the eight linkage groups in onion due to the relatively small number of segregating markers. Our studies to date have provided an unexpected revelation about the large genome of onion. Single cDNA and genomic clones detect duplicated RFLPs that show various degrees of linkage. It appears that the onion genome, like that of maize (Helentjaris et al., 1988), has undergone recent duplication(s). Onion chromosomes are primarily metacentric (Kalkman, 1984) and this suggests an evolutionary process of duplication, centric fusions (Robertson, 1916), and chromosome rearrangements that resulted in diploidization of the onion genome.

\section{FUTURE ANALYSES OF CHROMOSOME REGIONS CONTROLLING CORRELATED TRAITS}

Populations and hybrids of the storage onion are spring-sown, fallharvested, and stored throughout the winter before marketing. This production scheme requires that onions be dormant with little to no sprouting during 6 months of storage and hard enough to avoid malformation during bulk storage. The storage onion is pungent, usually to the point that most consumers will not eat it uncooked.
Onion flavor is affected by sulfur- (S) containing flavor precursors that produce the typical onion flavor when cleaved by alliinase enzymes (Schwimmer and Weston, 1961). Onion also is a source of antiplatelet or blood-thinning factors (Augusti, 1990), but to our knowledge there is no information on the genetic control of this trait. Because consumers eat vegetables with perceived health benefits and prefer mild onions (Stone et al., 1975), growers would benefit significantly from production of less pungent and well-storing hybrids with characterized health benefits. Storage ability, hardness, and soluble solids concentration (SSC) are heritable (Hosfield et al., 1977; Owens, 1951; Warid, 1952). Phenotypic correlations between large size, softness, low pungency, and poor storage ability have been reported (Bedford, 1984; Foskett, 1949; Hosfield et al., 1976, 1977). However, phenotypically correlated traits may not be conditioned by the same genes. The only reported genotypic correlation in onion is between high SSC and small bulb size (McCollum, 1966, 1968).

The segregating family from BYG15-23 x AC43 offers an excellent opportunity to identify and map quantitative trait loci controlling bulb quality, flavor, and antiplatelet activity. BYG15-23 is a hard, pungent, round, and well-storing inbred; AC43 is a soft, nonpungent, tall, poor-storing inbred. BYG15-23 exhibits about twice as much inhibition of platelet aggregation as an identical amount of AC43 (I. Goldman, Univ. of Wisconsin-Madison, unpublished data). Because of severe inbreeding depression in onion, at least 20 bulbs from each $\mathrm{F}_{3}$ family were caged and intercrossed by bees to generate $\mathrm{F}_{3}$ massed $\left(\mathrm{F}_{3} \mathrm{M}\right)$ progenies. In addition to restoring vigor to the families, the additional generation of recombination reduced linkage disequilibrium. We plan to undertake replicated field evaluations of these $F_{3} M$ families and use the low-density map to determine if independent chromosome regions conditioned phenotypically correlated with production (bulb shape, hardness, and storage ability), flavor (in cooperation with W. Randle, Univ. of Georgia-Athens), and antiplatelet (in cooperation with I. Goldman) attributes of onion. We hope to determine if we can develop less pungent and well-storing hybrids with characterized health benefits for domestic consumption and export.

\section{MOLECULAR-AIDED EXTRACTION OF MAINTAINER LINES FROM OPEN-POLLINATED POPULATIONS OF ONION}

The use of molecular markers to understand quantitatively inherited traits has been discussed extensively (reviewed by Tanksley, 1993). However, molecular markers are also useful as indirect selection tools for simply inherited traits with high evaluation costs. A case in point is the cytoplasmic-genic male-sterility (CMS) system used to produce hybrid-onion seed. S cytoplasm, discovered in 1925 (Jones and Emsweller, 1936), is the most common source of CMS. Sterile plants possess $\mathrm{S}$ cytoplasm and are homozygous recessive at the $M S$ locus (S msms). A dominant allele at this locus conditions male fertility (S MS-). Plants possessing normal, fertile (N) cytoplasm are fertile regardless of the genotype at the $M S$ locus (Jones and Clarke, 1943). Sterile lines are seed-propagated by crossing sterile plants ( $\mathrm{S} m s m s$ ) with maintainer plants ( $\mathrm{N} \mathrm{msms}$ ). To identify maintaining genotypes, onion breeders must pair fertile plants with known sterile plants and score the fertility of progeny from both parents, a process requiring 4 to 8 years. Restriction-enzyme analysis of the chloroplast (cp) and mitochondrial (mt) DNA have revealed polymorphisms between $\mathrm{S}$ and N cytoplasms (Courcel et al., 1989; Havey, 1993a, 1995; Holford et al., 1991). We identified five polymorphisms in the cpDNA and demonstrated that 12 of 31 open-pollinated populations of onion possess S-cytoplasm exclusively or a mixture of $\mathrm{S}$ and $\mathrm{N}$ cytoplasms (Havey, 1993a). Although CMS in onion may be due to incompatibility between the mitochondrial and nuclear genomes, Southern analyses of DNA from individual plants produced by crosses of S- and Ncytoplasmic plants supports maternal inheritance of the chloroplast and mitochondrial DNA; therefore, polymorphisms in the chloroplast DNA may be used to classify cytoplasms (Havey, 1995). Amplification by polymerase chain reaction (PCR) of a fragment that carries an autapomorphic 100-bp insertion in the cpDNA of $\mathrm{N}$ cytoplasm is a significantly quicker and cheaper alternative to crossing or Southern analysis. In an open-pollinated population, the frequency of a main- 
taining genotype $(\mathrm{N} m s m s)$ is the product of the frequencies of $\mathrm{N}$ cytoplasm and the msms genotype; e.g., in Texas Grano 1015Y, the frequency of maintainers $=($ proportion in $\mathrm{N}$ cytoplasm $) \times($ frequency of $m s)^{2}=(0.15) \times(0.11)^{2}=0.002$ (Havey, 1995). To be $95 \%$ confident of identifying one maintaining genotype from Texas Grano 1015Y, a breeder would have to complete 1663 pair-wise crosses between a sterile tester plant ( $\mathrm{S}$ sms ) and fertile plants from Texas Grano $1015 Y$. If the breeder first used organellar markers to classify cytoplasms and selected only those plants possessing $\mathrm{N}$ cytoplasm, only 247 pair-wise crosses would have to be completed to be $95 \%$ confident of identifying one maintaining genotype. This procedure represents an $85 \%$ reduction in the number of testcrosses compared to the Texas Grano 1015Y population per se (Havey, 1995). Therefore, for OP populations in a mixture of $\mathrm{N}$ and $\mathrm{S}$ cytoplasms, molecular identification of cytoplasms can significantly reduce the investment required to identify a maintaining genotype. More importantly, a breeder can calculate the expected cost to isolate a maintainer line and compare this cost with the anticipated revenues from sale of an eventual hybrid.

To test this technology, we used the PCR-based cpDNA marker to select N-cytoplasmic plants ( $\mathrm{N} m s m s, \mathrm{~N} M S m s$, or N MSMS) from the storage populations BYG, 'Mountain Danvers' (MD), and 'Sapporoki' (SKI). These N-cytoplasmic plants were then testcrossed to sterile plants (S msms) to establish the nuclear genotypes at the $M S$ locus. The testcross families were either all sterile, segregated 1 fertile : 1 sterile, or all fertile, corresponding to pollinators that were $\mathrm{N} m s m s, \mathrm{~N} M S m s$, or N MSMS, respectively. For these three populations, the frequency of the maintaining genotype fit expected values $\left(\chi^{2}=1.000, P=0.607\right)$. Therefore, molecular characterization of $\mathrm{N}$ and $\mathrm{S}$ cytoplasms significantly reduced the investment required to identify individual maintainer plants from OP populations. This experimental approach still requires that we complete testcrosses to establish the genotype at the nuclear $M S$ locus. The present goal of our laboratory is to tag this locus, allowing onion breeders to select genotypes at the seedling stage that maintain CMS and further reduce the number of testcrosses required to identify maintaining plants.

\section{CONCLUSIONS}

The development of a low-density genetic map for onion has been a challenge due to its relatively few polymorphisms as compared to other outcrossing diploid species, its biennial generation time, and its extremely large genome. Nevertheless, we are completing a map of $\approx 100$ molecular markers. This map will be a useful research tool as we endeavor to understand the genetics of correlated production, quality, flavor, and health-enhancing characteristics of onion and develop indirect selection tools useful in the selection of new value-added populations and hybrids.

\section{Literature Cited}

Albini, S. and G. Jones. 1988. Synaptonemal complex spreading in Allium cepa and Allium fistulosum. II. Pachytene observations: The SC karyotype and the correspondence of late recombination nodules and chiasmata. Genome 30:399-410.

Arumuganathan, K. and E. Earle. 1991. Nuclear DNA content of some important plant species. Plant Mol. Biol. Rpt. 9:208-218.

Augusti, K. 1990. Therapeutic and medicinal values of onions and garlic, p. 93108. In: H. Rabinowitch and J. Brewster (eds.). Alliums and allied crops. CRC Press, Boca Raton, Fla.

Bark, O.H. and M.J. Havey. 1995. Similarities and relationships among openpollinated populations of the bulb onion as estimated by nuclear RFLPs. Theor. Appl. Genet. 90:607-614.

Bedford, L. 1984. Dry matter and pungency tests on British grown onions. J. Natl. Inst. Agr. Bot. (U.K.) 16:58-61.

Bradeen, J.M. and M.J. Havey. 1995. Randomly amplified polymorphic DNA in bulb onion and its use to assess inbred integrity. J. Amer. Soc. Hort. Sci. 120:752-758.

Courcel, A. de, F. Veder, and J. Boussac. 1989. DNA polymorphism in Allium cepa cytoplasms and its implications concerning the origin of onions. Theor. Appl. Genet. 77:793-798.

Foskett, R. 1949. Relation of dry matter content to storage quality in some onion varieties and hybrids. MS Thesis, Iowa State Univ., Ames.

Gerdes, J. and W. Tracy. 1994. Diversity of historically important sweet corn inbreds as estimated by RFLPS, morphology, isozymes and pedigree. Crop Sci. 34:26-33.

Hadacova, V., E. Klozova, E. Hadac, V. Turkova, and K. Pitterova. 1981. Comparison of esterase isozyme patterns in seeds of some Allium species and in cultivars of Allium cepa L. Biol. Plant. (Prague) 23:376-380.

Havey, M.J. 1993a. A putative donor of S-cytoplasm and its distribution among open-pollinated populations of onion. Theor. Appl. Genet. 86:128-134.

Havey, M. 1993b. Onion breeding, p. 35-49. In: G. Kalloo and B. Berg (eds.). Genetic improvement of vegetable crops. Pergamon Press, Oxford.

Havey, M.J. 1995. Cytoplasmic determinations using the polymerase chain reaction to aid in the extraction of maintainer lines from open-pollinated populations of onion. Theor. Appl. Genet. 90:263-268.

Helentjaris, T., G. King, M. Slocum, C. Siedenstrang, and S. Wegman. 1985. Restriction fragment polymorphisms as probes for plant diversity and their development as tools for applied plant breeding. Plant Mol. Biol. 5:109118.

Helentjaris, T., D. Weber, and S. Wright. 1988. Identification of the genomic locations of duplicate nucleotide sequences in maize by analysis of restriction fragment length polymorphisms. Genetics 118:353-363.

Holford, P., J. Croft, and H. Newbury. 1991. Differences between, and possible origins of, the cytoplasms found in fertile and male-sterile onions (Allium cepa L.). Theor. Appl. Genet. 82:737-744.

Hosfield, G., G. Vest, and C. Peterson. 1976. A ten-parent diallel cross to evaluate inbred line performance and combining ability in onions. J. Amer. Soc. Hort. Sci. 101:324-329.

Hosfield, G., G. Vest, and C. Peterson. 1977. Heterosis and combining ability in a diallel cross of onions. J. Amer. Soc. Hort. Sci. 102:355-360.

Jones, H. and A. Clarke. 1943. Inheritance of male sterility in the onion and the production of hybrid seed. Proc. Amer. Soc. Hort. Sci. 43:189-194.

Jones, H. and G. Davis. 1944. Inbreeding and heterosis and their relation to the development of new varieties of onions. U.S. Dept. Agr. Tech. Bul. 874.

Jones, H. and S. Emsweller. 1936. A male sterile onion. Proc. Amer. Soc. Hort. Sci. 34:582-585.

Jones, H. and C. Peterson. 1952. Complementary factors for light-red bulb color in onions. Proc. Amer. Soc. Hort. Sci. 59:457.

Joshi, H. and J. Tandon. 1976. Heterosis for yield and its genetic basis in the onion. Indian J. Agr. Sci. 46:88-92.

Kalkman, E.R. 1984. Analysis of the C-banded karyotype of Allium cepa L. Standard system of nomenclature and polymorphism. Genetica 65:141148.

Labani, R. and T. Elkington. 1987. Nuclear DNA variation in the genus Allium L. (Liliaceae). Heredity 59:119-128.

Love, J. 1994. The US onion industry, 1995-2000. Onion World 10:15-19.

Magruder, R., R. Webster, H. Jones, T. Randall, G. Snyder, H. Brown, L. Hawthorn, and A. Wilson. 1941. Descriptions of types of principal American varieties of onions. U.S. Dept. Agr. Misc. Publ. 435, Washington, D.C.

McCollum, G. 1966. Heritability and genetic correlations of some onion bulb traits. J. Hered. 57:105-110.

McCollum, G. 1968. Heritability and genetic correlations of soluble solids, bulb size and shape in white sweet Spanish onion. Can. J. Genet. Cytol. 10:508-514.

McCollum, G. 1976. Onions and allies, p. 186-190. In: N. Simmonds (ed.). Evolution of crop plants. Longman, London.

Melchinger, A., M. Messmer, M. Lee, W. Woodman, and K. Lamkey. 1991. Diversity and relationships among U.S. maize inbreds revealed by restriction fragment length polymorphisms. Crop Sci. 31:669-678.

Owens, E. 1951. The inheritance of dry matter in onion bulbs. MS Thesis, Univ. of Idaho, Moscow.

Peffley, E. and O. Castillo. 1987. Polymorphism of isozymes within plant introductions of Allium cepa L. and A. fistulosum L. HortScience 22:956957.

Peffley, E., J. Corgan, K. Horak, and S. Tanksley. 1985. Electrophoretic analysis of Allium alien addition lines. Theor. Appl. Genet. 71:176-184.

Rabinowitch, H. 1988. Genetics and breeding: State of the art or too slow but not too late. 4th Eucarpia Allium Symp. 4:57-69.

Robertson, R. 1916. Taxonomic relationships in the chromosomes of Tettigidae and Agrididae: $\mathrm{V}$-shaped chromosomes and their significance in Agrididae, Locustidae, and Grylidae: Chromosomes and variation. J. Morphology 27:179-332.

Schwimmer, S. and W. Weston. 1961. Enzymatic development of pyruvic acid in onion as a measure of pungency. J. Agr. Food Chem. 9:301-304.

Stone, K., D. Young, E. Dixon, and D. Padberg. 1975. Consumer preferences for New York onions. Dept. Agr. Econ., Cornell Univ., Ithaca, N.Y.

Tanksley, S.D. 1993. Mapping polygenes. Annu. Rev. Genet. 27:205-233.

U.S. Dept. of Agriculture. 1992. Agricultural statistics. Washington, D.C. p. 390.

Warid, W. 1952. Inheritance studies in onion, Allium cepa L. PhD Diss., Louisiana State Univ., Baton Rouge. 